Accepted manuscript of an article published in Palliative Medicine Copyright $\odot 2018$ The authors. Reprinted by permission of SAGE Publications The definitive version of this article is available at https://doi.org/10.1177/0269216318783920

\title{
TITLE: Palliative Care in the Emergency Department: A Systematic Literature Qualitative Review and Thematic Synthesis \\ Running head: Palliative Care in the Emergency Department
}

\begin{abstract}
Authors:
Esther Cooper, Acute Care Common Stem Specialty Trainee, Whiston Hospital, St Helen's and Knowsley Teaching Hospitals NHS Trust, Mersey Deanery, Health Education England, UK; Hull York Medical School, University of Hull, Hull, UK Ann Hutchinson, Wolfson Palliative Care Research Centre, Hull York Medical School, University of Hull, Hull, UK

Zain Sheikh, Department of Head and Neck Surgery, York Hospital, York Teaching Hospitals NHS Foundation Trust; Hull York Medical School/Department of Health Sciences, University of York, UK Paul Taylor, School of Health and Related Research (ScHARR), University of Sheffield, UK; St Luke's Hospice, Sheffield, UK

Will Townend, Department of Emergency Medicine, Hull Royal Infirmary, Hull and East Yorkshire Hospitals NHS Trust, Hull, UK

Miriam J Johnson, Wolfson Palliative Care Research Centre, Hull York Medical School, University of Hull, Hull, UK
\end{abstract}

\section{Author for correspondence:}

Miriam J Johnson, Wolfson Palliative Care Research Centre, Hull York Medical School, Allam Medical Building, University of Hull, Cottingham Road, Hull, UK HU6 7RX. E: miriam.johnson@hyms.ac.uk; T: 01482463309

Word count: 3,667 (3 tables, 1 figure, 5 online tables) 


\title{
TITLE: Palliative Care in the Emergency Department: A Systematic Literature Qualitative Review and Thematic Synthesis \\ Running head: Palliative Care in the Emergency Department
}

\begin{abstract}
Authors:
Esther Cooper, Acute Care Common Stem Specialty Trainee, Whiston Hospital, St Helen's and Knowsley Teaching Hospitals NHS Trust, Mersey Deanery, Health Education England, UK; Hull York Medical School, University of Hull, Hull, UK Ann Hutchinson, Wolfson Palliative Care Research Centre, Hull York Medical School, University of Hull, Hull, UK

Zain Sheikh, Department of Head and Neck Surgery, York Hospital, York Teaching Hospitals NHS Foundation Trust; Hull York Medical School/Department of Health Sciences, University of York, UK Paul Taylor, School of Health and Related Research (ScHARR), University of Sheffield, UK; St Luke's Hospice, Sheffield, UK

Will Townend, Department of Emergency Medicine, Hull Royal Infirmary, Hull and East Yorkshire Hospitals NHS Trust, Hull, UK

Miriam J Johnson, Wolfson Palliative Care Research Centre, Hull York Medical School, University of Hull, Hull, UK
\end{abstract}

\begin{abstract}
Author for correspondence:
Miriam J Johnson, Wolfson Palliative Care Research Centre, Hull York Medical School, Allam Medical Building, University of Hull, Cottingham Road, Hull, UK HU6 7RX. E: miriam.johnson@hyms.ac.uk; T: 01482463309
\end{abstract}

Word count: 3,667 (3 tables, 1 figure, 5 online tables) 


\title{
ABSTRACT
}

Background: Despite a fast-paced environment, the emergency clinician has a duty to meet the palliative patient's needs. Despite suggested models and interventions, this remains challenging in practice.

\begin{abstract}
Aim: To increase understanding of these challenges by exploring the experience of palliative care patients and their families and informal carers attending the emergency department, and of the clinicians caring for them.
\end{abstract}

Design: Qualitative systematic literature review and thematic synthesis. Search terms related to the population (palliative care patients, family carers, clinicians), exposure (the emergency department) and outcome (experience). The search was international but restricted to English, and used a qualitative filter. Title, abstracts and retrieved full texts were reviewed independently by two reviewers against predefined inclusion criteria arbitrated by a third reviewer. Studies were appraised for quality but not excluded on that basis.

Data Sources: MEDLINE [1946-], Embase[1947-], CINAHL [1981-] and PsycINFO [1987-] with a bibliography search.

Results: 19 papers of 16 studies were included from Australia $(n=5)$, the United Kingdom $(n=5)$ and United States $(n=9)$ representing 482 clinical staff involved in the emergency department (doctors, nurses, paramedics, social workers, technicians), 61 patients and 36 carers. Nine descriptive themes formed three analytic themes: "Environment and Purpose"; "Systems of Care and Interdisciplinary Working" and "Education and Training".

Conclusions: Provision of emergency palliative care is a necessary purpose of the emergency department. Failure to recognise this, gain the necessary skills, or change the systems needed for an environment better suited to its delivery perpetuates poor implementation of care in this environment.

Key words: emergency department; emergency care; palliative; experience; qualitative 


\section{What is already known about the topic?}

- The emergency department is a chaotic and fast-paced environment with a primary aim of rapid assessment and acute clinical care.

- However, the emergency physician also has a duty to meet the palliative patient's needs for care, comfort, and compassion; delivery of these goals is variably met.

- Models of palliative care in the emergency department are described, but implementation is poor

\section{What this paper adds}

- Multiple level issues contribute to suboptimal care for palliative care patients and their families in the ED; system and organisational, clinician education and training, interdisciplinary and cross-setting working and clinician attitudes focussing on acute restorative care rather than palliation.

- These findings provide explanation for the persisting poor implementation of best practice

\section{Implications for practice, theory or policy}

- Problems at all levels need to be addressed, but the foundational need is that care of palliative patients is recognised at all levels as a legitimate purpose of the ED. 


\section{INTRODUCTION}

Emergency departments (EDs) receive patients with a wide range of clinical conditions from those with acute trauma, through to those with terminal illness. ${ }^{1}$ The primary focus of the ED is on rapid assessment and acute clinical care with a view to transfer of patients to appropriate clinical contexts in a timely and efficient manner. ${ }^{2}$

Palliative care is defined by the World Health Organisation as an approach which "improves the quality of life of patients and their families ... with life-threatening illness, through the ... impeccable assessment and treatment of pain and other problems" and is applicable alongside treatments intended to prolong life. ${ }^{3}$ Such an approach can be difficult during an initial attendance at the ED, especially where crucial information about the patient's clinical history or management plan may not be readily available. Furthermore, the fast-paced and sometimes even chaotic context of the ED does not provide an easy environment for advance care planning, communication and provision of comfort measures. ${ }^{4}$

The need for attention to symptoms and other palliative care needs in the ED cannot be dismissed as a rarity or completely unavoidable. ${ }^{5}$ For example, breathlessness is a common symptom in people with chronic cardio-respiratory conditions, which typically worsens with disease progression. ${ }^{6,7}$ Distressing respiratory symptoms is one of the most common reasons for palliative care patients to attend the ED. ${ }^{8}$ Acute-on-chronic breathlessness is one of the most frightening experiences for patients and their carers and is associated with ED attendance. ${ }^{9,10}$ Nevertheless, a significant proportion of those attending due to acute-on-chronic breathlessness are discharged the same day, ${ }^{9}$ suggesting that their attendance was not primarily driven by acute deterioration of the underlying pathology. The needs of these patients could perhaps be better met by management co-ordinated in the community. ${ }^{9}$ Attendance may, of course, be appropriate and, whether admitted or not, for people living with chronic breathlessness ${ }^{11}$ an attendance at the ED where exclusion of a diseaserelated exacerbation is the sole focus of the encounter may miss an opportunity for their palliative care to be optimised and to prevent re-attendance.

In 2008, the American College of Emergency Physicians recognised that despite a chaotic and fastpaced environment, the emergency physician has a duty to meet the palliative patient's needs for care, comfort, and compassion. ${ }^{12}$ Observational study has highlighted some of the reasons why people with advanced cancer present to the ED, ${ }^{13}$ and various models of incorporating palliative care into the ED have been described, ${ }_{14}^{14}$ but with little evidence of patient benefit. ${ }^{15}$ However, this remains a challenge in practice. ${ }^{4,16-18} \mathrm{~A}$ broad review of 160 papers described a number of relevant problems: uncertainty, issues around quality of life, cost, the relationship between ED and other health services, quality of hospital care and ethical and social issues. ${ }^{19}$

Qualitative research can offer insights into how patients, carers and healthcare professionals experience the provision of palliative care in the ED, help explain described problems and point to solutions. The aim of this qualitative systematic literature review and thematic synthesis was to raise awareness of the experience of a broader population of palliative care patients and their families 
and carers attending the ED, together with the insights of clinicians caring for them thereby increasing understanding why implementation of good practice remains difficult.

\section{METHOD}

The search strategy was pre-planned. The following electronic databases (MEDLINE [1946-], Embase [1947-], CINAHL [1981-] and PsycINFO [1987-]) were searched in January 2016 for published journal

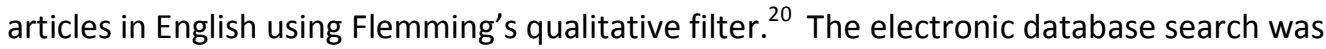
supplemented by a manual search of citations from key existing reviews on similar subject matter. The search strategy and search terms are shown in the online eTable 1 and modified for each database. Terms were developed to address the population (palliative care), exposure (the ED) an outcome (experience). Titles and abstracts were reviewed by two independent reviewers (E.C. and Z.S.) against predefined inclusion criteria (Table 1). Discrepancies were resolved by discussion and a third independent reviewer (M.J.J.). This process was then repeated reviewing the full texts. All studies identified for inclusion were appraised by E.C. for quality (including congruity, influence of the researcher, representation of participant voice) using the QARI Critical Appraisal Checklist for Interpretive and Critical Research. ${ }^{21}$ Studies were not excluded on the basis of quality, but quality was taken into account with regard to the interpretation of findings.

Table 1. Eligibility criteria

\begin{tabular}{|c|c|}
\hline Inclusion Criteria: & Exclusion Criteria: \\
\hline $\begin{array}{l}\text { - } \quad \text { English language full reports } \\
\text { Design: primary qualitative empirical } \\
\text { research } \\
\text { - } \quad \text { Population: adult* palliative care patients } \\
\text { attending the emergency department, carers } \\
\text { or clinicians, mixed adult/children } \\
\text { populations where data from adults could be } \\
\text { extracted } \\
\text { Outcome: studies addressing any aspect of } \\
\text { participants' experience } \\
\text { * aged } 18 \text { years or older }\end{array}$ & 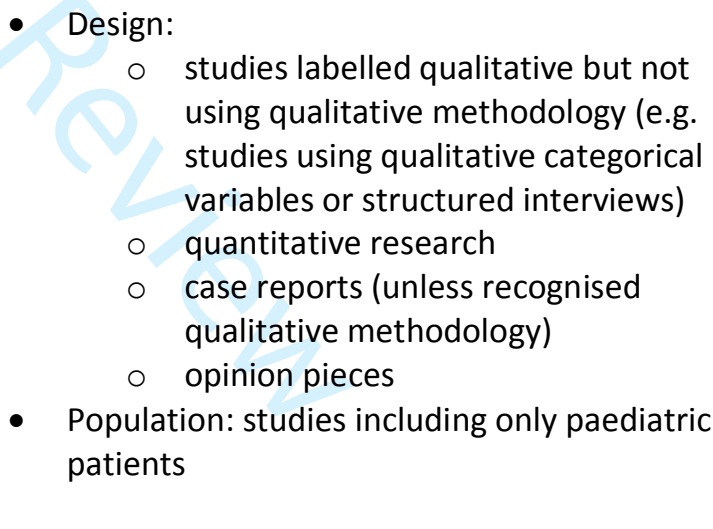 \\
\hline
\end{tabular}

Data were extracted from included papers by E.C. using a bespoke data extraction form. Contextual information about each study was extracted, together with all primary data (direct and paraphrased participants' quotations) where available.

Data were synthesized using thematic synthesis ${ }^{22}$ thereby allowing the context of each study to be taken into account in the production of a generalisable whole. ${ }^{23}$ Thematic synthesis was chosen because it uses a realist approach (external reality can be adequately represented) consistent with the epistemological position held by the researchers. ${ }^{24}$ In view of the heterogeneity of the included studies in terms of their research aims and populations studied, meta-ethnography was not suitable, and only primary and paraphrased quotes from participants were extracted from each paper and 
RESULTS

\section{Selected studies:}

Literature searching retrieved eligible 19 papers covering 16 studies from Australia $(n=5)$, the United Kingdom $(n=5)$ and United States $(n=9)$ representing 482 clinical staff, 61 patients and 36 carers (see Figure 1). A summary of the included articles is provided in Table 2 but most studies included clinicians only $(n=11)$. The remaining 8 studies had a variable mix of patients with family carers and/or clinicians.

then coded. EC read the papers and added codes by hand using Atlas.ti version 7, Scientific Software Development $\mathrm{GmbH}$, Berlin, to manage the data. The synthesis was performed in three stages: the first stage was line-by-line coding searching for concepts in the primary research findings (direct and paraphrased quotations) of each study on the experience of patients with palliative care needs attending the ED (E.C). Secondly, these codes were then refined, and through an inductive reasoning process organised into descriptive themes. Thirdly, supported by A.H., the analytical themes emerged following a process of reflection on the descriptive themes involving discussion and interpretation (A.H, E.C., M.J. and W.T) to provide a broad understanding of the experience of palliative care in the ED. E.C. and W.T. are ED clinicians, A.H. is a health researcher and M.J. is a professor of palliative medicine. All will have brought their previous experiences to bear in interpretation, but transparency of the method, independent selection of and extraction from primary studies and group discussion provides rigour to the review and synthesis process. The synthesis is reported in accordance with the Enhancing Transparency in Reporting the synthesis of Qualitative research (ENTREQ) guidance. ${ }^{25}$ 


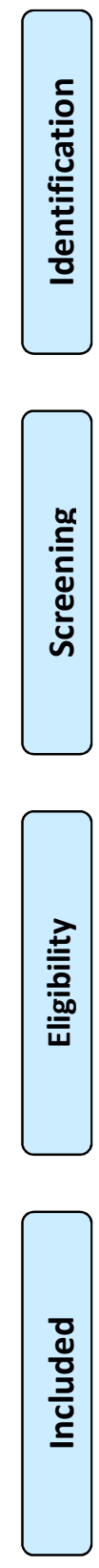

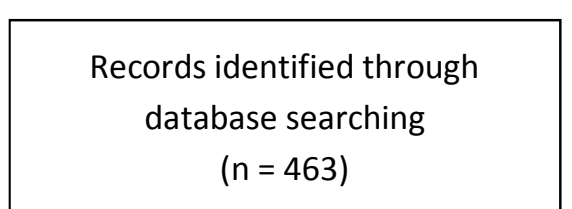
$(n=463)$
Additional records identified through other sources $(n=5)$
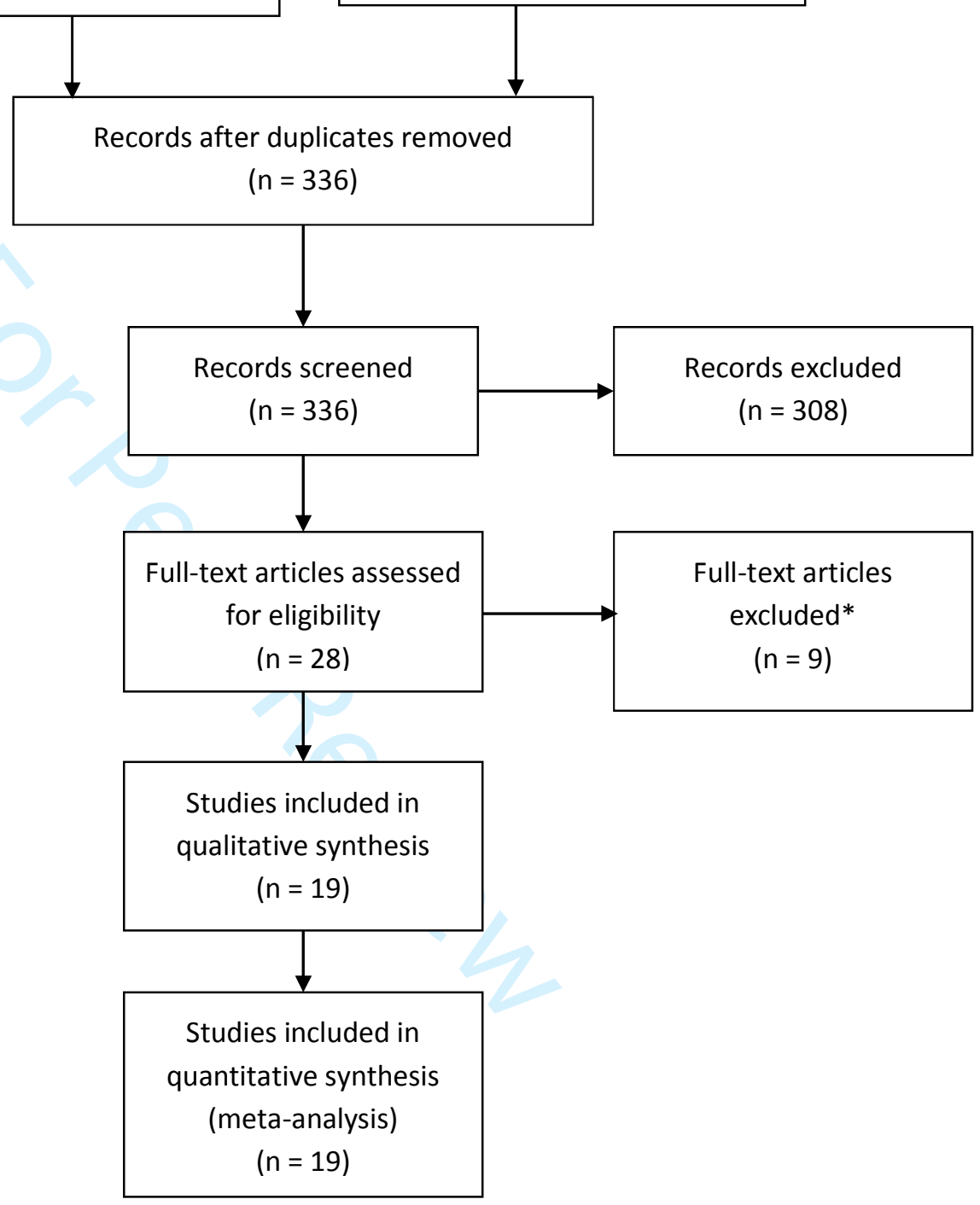

Figure 1. PRISMA flow chart. *Papers were excluded if they did not use qualitative methods $(n=5)$, did not report on emergency department specific situations $(n=2)$ or only reported on acute or traumatic deaths or had no reference to palliative care $(n=2)$

<<insert Table 2 about here〉> 


\section{Quality of included studies}

Most studies presented clear aims and objectives, described the qualitative methods used and the techniques for data collection and had congruity between objectives, methods and interpretation of results (see eTable 2 QARI Appraisal). They also appeared to adequately represent the views of participants throughout the analysis. In keeping with qualitative research methods, sample sizes were small, but adequate for the method described. The purpose of qualitative research is not to produce generalizable results and this was discussed by all authors with regards to the limitations of the study limited capacity for generalizability as is common in such qualitative research. ${ }^{26}$

\section{Thematic synthesis}

Coding of these 19 articles revealed 31 free text codes which were divided into nine descriptive themes. These themes were then condensed further into three analytical themes that described the most prominent aspects of the experience of palliative care patients, relatives and healthcare providers in the ED. These three analytic themes form the basis of the discussion below. They are: "Environment and Purpose"; "Systems of Care and Interdisciplinary Working" and "Education and Training" (Table 3).

Table 3. Relationships between themes

\begin{tabular}{|c|c|c|}
\hline Analytical themes & Themes & Codes \\
\hline \multirow[t]{2}{*}{$\begin{array}{l}\text { Environment and } \\
\text { purpose }\end{array}$} & $\begin{array}{l}\text { Environmental } \\
\text { factors }\end{array}$ & $\begin{array}{l}\text { - } \text { Noisy environment } \\
\text { - } \text { Long waiting times } \\
\text { - } \text { Time pressures } \\
\text { - } \text { Resource limitation } \\
\text { - } \text { Low prioritisation } \\
\text { - } \text { Segregation and isolation of the dying } \\
\text { - } \text { ED not an ideal place to die }\end{array}$ \\
\hline & Providing care & $\begin{array}{l}\text { - } \text { Role of palliative care } \\
\text { - Symptom control } \\
\text { - Clinicians' comfort in providing care } \\
\text { - } \quad \text { Building relationships with patients } \\
\text { - } \text { Caring for relatives }\end{array}$ \\
\hline \multirow{4}{*}{$\begin{array}{l}\text { Systems of care } \\
\quad \text { and } \\
\text { interdisciplinary } \\
\text { working }\end{array}$} & Communication & $\begin{array}{l}\text { - } \quad \text { Breaking bad news } \\
\text { - } \quad \text { Nuality of communication } \\
\text { - }\end{array}$ \\
\hline & $\begin{array}{l}\text { Interdisciplinary } \\
\text { working }\end{array}$ & $\begin{array}{l}\text { - } \text { Communication between specialties } \\
\text { - Transfer of information } \\
\text { - Appropriate clinicians initiating discussion }\end{array}$ \\
\hline & Decision making & $\begin{array}{l}\text { - } \quad \text { Patient involvement } \\
\text { - Influence of relatives }\end{array}$ \\
\hline & Accessing care & $\begin{array}{l}\text { - Relatives instigating escalation of care } \\
\text { - Lack of access to community palliative care } \\
\text { - } \quad \text { Lack of direct access to secondary care } \\
\text { - Palliative care consultations in the ED }\end{array}$ \\
\hline Education and & Education & - Need for education \\
\hline
\end{tabular}




\section{Environment and purpose (eTable 3)}

Patients, relatives and clinicians commented on the impact of the environment and perceived purpose of the ED on the quality of care received by patients requiring palliative and end of life care. The unavoidable noise and busyness of departments was frequently remarked upon as an uncomfortable situation, in particular for patients at the end of life. ${ }^{27,28}$

"I suppose it must be horrible if you are at the end of your life and you are in resus [the resuscitation room] because it is so noisy at times. But I can't see how they could overcome that apart from obviously trying to get a side room on the ward which they do but then you have to wait. There isn't many side rooms, it's never like we need a side room and one comes up straight away." [ED nurse $]^{17}$

In addition to this, anxieties were increased by long waiting times. ${ }^{29}$ Time pressures and resource limitation were given as the reason for palliative patients being a low priority. ${ }^{27,}{ }^{29}$ Ultimately many members of staff found balancing the tension between efficiency and optimal care very challenging. ${ }^{28,30}$

"When you're being forced to wait for so long and in pain it feels like the opposite of caring." [Palliative care nurse $]^{29}$

With the aim of providing privacy and space for patients and relatives, dying patients were frequently separated from other patients in the ED in corner rooms and relatives' rooms and then transferred out of the department as quickly as possible. ${ }^{18}$ The encouragement of communication between patients and their relatives was seen to facilitate more appropriate treatment options and goals of care. ${ }^{4,27,31}$ However, some EDs had little space for family members to remain with their relative at a distressing time or for confidential and sensitive discussions surrounding goals of care. ${ }^{29}$

Although most ED clinicians recognised and accepted that care of the dying was a reasonable demand and could be rewarding, they considered the ED to be an inappropriate place to die ${ }^{30}$ and a suboptimal environment for people with advanced cancer. ${ }^{29}$ This led to a tension between the belief that ED clinicians should be able to provide palliative care and the concern that they were unable to provide this care well despite their best efforts. ${ }^{32}$

"Helping someone die in comfort and dignity ... is some of the most rewarding clinical experiences I have. I feel I have not been able to completely provide the care, respect and dignity for the patient who dies within the ED." [Healthcare professional] ${ }^{30}$ 
ED clinicians agreed that they should provide symptomatic relief for acute problems experienced by those with advanced and terminal disease. However, concerns about ineffective symptom management and poor communication were identified as a significant cause of dissatisfaction with the patients' ED experience. ${ }^{18,28,33-38}$ In addition, ED clinicians vary in confidence in their palliative care skills. ${ }^{27,30,39}$ Being aware of and keeping the patient's wishes central to decision making was felt to be key to providing a "good death" in the ED. ${ }^{18,40}$ Building relationships with patients ${ }^{35}$ was seen as particularly challenging, but recognised as key to good quality of care especially when advocating for the patient at a time of crisis $^{17}$ along with caring for accompanying relatives. ${ }^{33,41}$

Systems of care and interdisciplinary working (eTable 4)

ED users emphasised the need for clear communication ${ }^{17,28,36}$ noting problems when this did not occur. ${ }^{33}$ Clinicians found it difficult to break bad news to end-of-life patients, exacerbated by the perceived pressures to clear space for the next ED patient. ${ }^{18}$ Barriers to sensitive discussions included language barriers, differing cultural and/or spiritual beliefs and limited health literacy. ${ }^{36}$

"We found a great lack of communication to be quite honest because they [the ED staff] were very busy ... so the information wasn't very forthcoming. It wasn't until Dad got here [the Specialist Palliative Care Unit] that answers started to become apparent. I think from our point of view, purely from the frustration as a family member, I wanted to know what was going off. The lack of information was infuriating." [Relative] ${ }^{33}$

Communication among clinicians and between services was seen as important but fraught with difficulties, compromised by other demands on time. ${ }^{32}$ Poor transfer of information between those involved in a patient's care and a lack of clinical information about previously negotiated goals of care led to active, and potentially inappropriate invasive, treatment by default. ${ }^{30}$ However, ED clinicians frequently reported concerns that discussions with regards to ceilings of medical treatment had not been undertaken prior to attendance at the ED, even for patients with apparent progressing disease. ${ }^{27,32}$ Clinicians felt particularly uneasy where the patient appeared unaware of their diagnosis or stage of disease. ${ }^{35}$ It was felt that such important discussions should occur with a doctor who knew the patient well. ${ }^{32}$

"Part of the problem involves being able to communicate effectively with people who know the patients better-their primary care providers, their oncologists - but who aren't there at the $[E D]$ at the time the patient comes in." [ED physician $]^{27}$

Unawareness of the severity of illness extended to relatives, who were seen to have great influence on the care provided in ED and often swayed the decision whether or not to provide palliative or curative care measures. This challenged physicians as it could be difficult to meet the needs of both the patient and the family, especially when the family expected heroic measures. ${ }^{36}$ This conflict between patients, relatives and clinicians often caused moral distress. ${ }^{34}$ This distress was reported in conflict between the patient's previously expressed wishes and their family ${ }^{42}$ and between clinicians due to the perceived unrealistic expectations of some inpatient teams. ${ }^{30}$ 
"The patient came with a comfort measures only/do-not-hospitalize piece of paperworkvery demented patient, couldn't even speak in complete sentences, couldn't process anything that we said, and that was her baseline according to all of the records that we received. The family member reversed everything while I was on the phone, saying 'I do want her hospitalized, and I want you to do everything possible." [ED physician] ${ }^{27}$

Families also often prompted patients to access emergency care ${ }^{42}$ and despite previous discussions and education with regards to the patient's condition and prognosis. ${ }^{34}$ The patient was often disgruntled at having been taken to ED once their condition improved and they regained capacity. ${ }^{28}$

In general, patients described ED attendance as unwanted or a last resort, but an unavoidable consequence of lack of access to services, including palliative care expertise, in the community, especially when crises occurred out-of-hours ${ }^{36}$ or in secondary specialist care settings. ${ }^{29}$ This was seen by ED staff as a failure of clinicians' long term care of patients ${ }^{32}$ and that the presenting symptoms could have been pre-empted ${ }^{29}$ or the patient transferred to a suitable care setting with access to expertise in palliative care. ${ }^{42}$

“Optimal care for advanced cancer patients would involve remaining in the community and avoiding ED attendance and hospital admission. ED attendance was widely seen as a failure and the ED a less than ideal environment for patients with advanced cancer. I think we go to great lengths to avoid attendances to emergency departments unless we really have to." [PC clinician $]^{32}$

The inadequacy of current systems of care leading to ED attendances for patients with palliative care needs was highlighted in several studies. Suggestions included a "palliative care hotline" to improve access to useful clinical and organisational information or access to specially trained nurses able to be called on as required. ${ }^{27}$ Eligibility criteria for palliative care consultation would help standardise the use of palliative care services and increase palliative care visibility in the ED. ${ }^{36}$ Specialist palliative care consults in ED were particularly welcomed by patients and relatives previously familiar with the palliative care team as either an inpatient or outpatient. ${ }^{28}$

\section{Education and training (eTable 5)}

As well as requesting palliative care consultations, ED clinicians were keen to develop their own skills in palliative care, ${ }^{35}$ symptom control ${ }^{29}$ and communication skills. ${ }^{27,43}$ A lack of palliative care training within the emergency medicine curriculum was identified as a barrier to the provision of palliative care ${ }^{27}$ and addressing this with education of both medical and nursing ED staff was seen as a way to improve care. ${ }^{33,36}$ The collaboration between ED and palliative care teams was highlighted as a potential way to overcome these educational shortfalls. ${ }^{35}$ The use of palliative care nurse champions $^{31,35,42}$ and the provision of educational materials, presentations and courses tailored to the needs of ED staff were suggested as ways to achieve this. ${ }^{36}$ 


\begin{abstract}
"Palliative pain control is a very specialised area. I think most EDs are quite blunt with how they manage pain, and certainly the options that are considered by palliative care specialist
\end{abstract} may not even be known about by a lot of ED doctors." [ED consultant ${ }^{29}$

Particular gaps in knowledge and skills included decisions about antibiotic or intravenous fluids in the context of comfort care, ${ }^{27}$ the medico-legal aspects of withholding futile interventions ${ }^{30,35}$ and the interpretation and application of advanced directives (ADs). ${ }^{27,30,43}$ These concerns affected both the ED providers and formal carers (particularly in nursing homes) who often chose to transfer patients to the ED against their clinical judgement for fear of repercussions with the family or litigation. ${ }^{42}$

"People have a phobia, they think that if they have an AD we're going to kill them or something or use them for organ donation." [Healthcare professional] ${ }^{43}$

Promotion of ADs was considered important in encouraging patients to plan for foreseeable events in their disease progression. ${ }^{16}$ Communication skills were seen as another gap, ${ }^{44}$ and ensuring patients and family members were aware of the likely progression of illness was felt to minimise ED attendances and also improve quality of care. ${ }^{29}$ They identified recognition of poor prognosis as a key educational need including the significance of symptoms as a trigger for transfer to the ED, ${ }^{27,28}$ carer burden ${ }^{42}$ and the role of a hospice. ${ }^{34}$

\title{
DISCUSSION
}

This systematic review of literature and thematic synthesis described the experiences of palliative care patients, relatives and clinicians in the ED and the potential conflicts between the goals of emergency care and palliative care. The synthesis of multiple, independent studies provided three overarching themes to illustrate areas of tension that affected the successful delivery or experience of care: environment and purpose, system of care and interdisciplinary working, and education and training.

Although great effort has been put into improving access to palliative care ${ }^{45}$ and its provision in the community, ${ }^{46}$ the findings of this review suggest some palliative care patients will always need to present to the ED. There was clear congruence between the role of the ED and palliative care in managing the physical symptoms of palliative patients at times of crisis, reflected by the wide acceptance of ED staff to provide symptomatic relief. However, there was conflict of opinion with regards to how well this is currently performed and what level of skill should be expected of ED staff. Although ED clinicians should be equipped to deal with emergency palliative care issues - poorly controlled symptoms, acute conditions such as spinal cord compression and acute unpredictable deteriorations - the task of advance care planning was felt to sit better with clinicians with an established relationship with the patient. The brief nature of the healthcare professional-patient relationship in the ED was a key issue. Barriers to high quality communication echoed those identified in existing literature: the fast pace and limited resources of the ED, ${ }^{47}$ language barriers and 
cultural or religious differences. ${ }^{48}$ Inexperience left ED physicians uncertain how to raise difficult issues surrounding future care.

System barriers to the transfer of information were a recurrent issue that could be addressed by services such as "coordinate my care". ${ }^{49}$ ED clinicians' access to a personalised plan of care would also facilitate communication with relatives to overcome conflicts between their wishes and those of the patient and between conflicting wishes of multiple relatives. Provision of empathetic palliative care can cause emotional and moral distress for clinicians. Systems of support at an institutional level such as counselling and case discussions have been called for in other specialties (e.g. paediatrics, ${ }^{50}$ intensive care ${ }^{51,52}$ and rapid response teams ${ }^{53}$ ) caught in the tension between saving lives and caring for the dying which may be comparable. ${ }^{4}$

Although attendance at the ED is often a "last resort", it is currently often unavoidable, in particular when clinical or emotional support is required out-of-hours. Access to emergency community-based generalist and specialist palliative care remains patchy.

Consistent with other calls for education about end of life care for emergency clinicians, ${ }^{54}$ training should address the interdisciplinary educational shortfalls at both undergraduate and postgraduate levels - including senior clinicians. ${ }^{55}$ Involvement of palliative care clinicians for patients with complex needs will facilitate learning and also provide support for the emergency teams.

Education should extend beyond clinicians, to include patients and relatives. Important areas include likely disease progression, facilities to manage symptoms at home, advance care planning and the role of the hospice. Education and specialist support in dealing with the emotional challenge of providing care at home may also be required.

\section{Implications for clinical practice and future research}

A formal acceptance by clinicians in the ED that their role is not only "heroic" ${ }^{36}$ or "lifesaving" ${ }^{17}$, but also to provide care for those beyond rescue is necessary. The inclusion of palliative care competencies in the curricula for specialist medical trainees and training for ED nurses would better equip the staff with skills and emphasise that palliative care is part of their job. Advanced communication skills training should be as much a key part of training for ED clinicians as it is for primary care, oncology and palliative care clinicians. Senior clinicians should be included in training to ensure they provide leadership in this culture change. ${ }^{55-57}$

Such change would be supported by a closer interdisciplinary collaboration between existing palliative, primary and emergency care specialties and allow both emergency and palliative care providers to negotiate their specific roles in the provision of care and access training about symptom management from the palliative care team. Usual care team clinicians (both hospital and primary care) should be aware of the impact of abdicating responsibility with regard to advance care planning and access to the patient's clinical record, including such discussions, should be made available to ED clinicians.

From these data, models whereby ED clinicians perceive palliative care as the specialist palliative care team's responsibility, with their only role being identification of "the palliative patient" may risk an unsustainable and resource intensive load on specialist services, ${ }^{58}$ or failure to "see" the patient for which ED clinicians perceive they have inadequate skills. However, changes which include the 
development of palliative care "champions" amongst the ED workforce ${ }^{59}$ in partnership with specialist providers, with an expectation that all ED staff gain basic competencies in palliative care, alongside practical, low cost adaptations (private space, curtains, chairs for family) would appear possible, welcomed by ED clinicians and helpful for patients and families. Further research into the best models of service configuration and delivery, including workforce education, training and communication requirements will be difficult, ${ }^{60}$ but not insurmoutable ${ }^{61}$ and is urgently needed ${ }^{14}$

\section{Limitations of this study}

Due to team resource limitations and the challenges of maintaining code meaning in translation, this study was limited to English-language papers. Also, even with the best search strategy, key papers may have been omitted. Despite these limitations, significant findings have been portrayed that could have a positive impact on the experience of palliative care patients attending the ED.

\section{CONCLUSIONS}

Some palliative care patients will need the ED. Issues regarding the environment and purpose, system of care and interdisciplinary working, and education and training influence the delivery and experience of care. Only when the importance of palliative care in the ED is recognised by both those that work there and those in palliative care and the necessary skills gained, can systems begin to change to enable an environment better suited to its delivery. Failure to do so will perpetuate poor implementation of palliative care in this environment.

\section{DISCLOSURES AND ACKNOWLEDGEMENTS}

\section{Declarations}

EC conceived the research question; WT, EC, MJJ, AH developed the protocol; EC conducted the search; EC, ZS assessed for inclusion; AH provided methodological guidance; EC, AH, WT, MJJ, PT analysed and/or interpreted the data; EC wrote the first draft, all authors contributed to drafts and approved the final version.

\section{Funding}

No funding was received for this study.

Declaration of conflicts of interest.

The authors declare no conflicts of interest

Research ethics and patient consent. 


\begin{abstract}
Not applicable
Data management and sharing
\end{abstract}

The search strategy and extracted data are presented and thus available. 


\section{REFERENCE LISTReference List}

1. Chan GK. End-of-life models and emergency department care. Acad Emerg Med 2004; 11(1):79-86.

2. Lecky F, Benger J, Mason S, Cameron P, Walsh C. The International Federation for Emergency Medicine framework for quality and safety in the emergency department. Emerg Med J 2014; 31(11):926-929.

3. WHO Definition of Palliative Care. http://www.who.int/cancer/palliative/definition/en/. 2013. 28-7-2013.

Ref Type: Electronic Citation

4. Savory EA, Marco CA. End-of-life issues in the acute and critically ill patient. Scand J Trauma Resusc Emerg Med 2009; 17:21.

5. Green E, Gott M. Palliative care in the emergency department: avoidable or appropriate? $\mathrm{Br}$ J Hosp Med (Lond) 2016; 77(12):674-675.

6. Currow DC, Smith J, Davidson PM, Newton PJ, Agar MR, Abernethy AP. Do the trajectories of dyspnea differ in prevalence and intensity by diagnosis at the end of life? A consecutive cohort study. J Pain Symptom Manage 2010; 39(4):680-690.

7. Johnson MJ, Bland JM, Gahbauer EA et al. Breathlessness in Elderly Adults During the Last Year of Life Sufficient to Restrict Activity: Prevalence, Pattern, and Associated Factors. J Am Geriatr Soc 2016; 64(1):73-80.

8. Green $\mathrm{E}$, Gott $\mathrm{M}$, Wong J. Why do adults with palliative care needs present to the emergency department? A narrative review of the literature. Progress in Palliative Care 2016; 24(4):195203.

9. Hutchinson A, Pickering A, Williams P, Bland JM, Johnson MJ. Breathlessness and presentation to the emergency department: a survey and clinical record review. BMC Pulm Med 2017; 17(1):53.

10. Niska R, Bhuiya F, Xu J. National Hospital Ambulatory Medical Care Survey: 2007 emergency department summary. Natl Health Stat Report 2010;(26):1-31.

11. Johnson MJ, Yorke J, Hansen-Flaschen J et al. Towards an expert consensus to delineate a clinical syndrome of chronic breathlessness. European Respiratory Journal 517; in press.

12. Ethical issues at the end of life. Ann Emerg Med 2008; 52(5):592.

13. Henson LA, Gao W, Higginson IJ et al. Emergency department attendance by patients with cancer in their last month of life: a systematic review and meta-analysis. J Clin Oncol 2015; 33(4):370-376.

14. Grudzen CR, Stone SC, Morrison RS. The palliative care model for emergency department patients with advanced illness. J Palliat Med 2011; 14(8):945-950. 
15. da Silva SD, Nunes CM, Gomes B. Effectiveness of Emergency Department Based Palliative Care for Adults with Advanced Disease: A Systematic Review. J Palliat Med 2016; 19(6):601609.

16. Bailey C, Murphy R, Porock D. Professional tears: developing emotional intelligence around death and dying in emergency work. J Clin Nurs 2011; 20(23-24):3364-3372.

17. Bailey CJ, Murphy R, Porock D. Dying cases in emergency places: caring for the dying in emergency departments. Soc Sci Med 2011; 73(9):1371-1377.

18. Decker K, Lee S, Morphet J. The experiences of emergency nurses in providing end-of-life care to patients in the emergency department. Australas Emerg Nurs J 2015; 18(2):68-74.

19. Forero R, McDonnell G, Gallego B et al. A Literature Review on Care at the End-of-Life in the Emergency Department. Emerg Med Int 2012; 2012:486516.

20. Flemming K, Briggs M. Electronic searching to locate qualitative research: evaluation of three strategies. J Adv Nurs 2007; 57(1):95-100.

21. The Joanna Briggs Institute: Joanna Briggs Institute Reviewers.2008, The Joanna Briggs Institute, 2008. 2017.

Ref Type: Report

22. Thomas J, Harden A. Methods for the thematic synthesis of qualitative research in systematic reviews. BMC Med Res Methodol 2008; 8:45.

23. Barnett-Page $E$, Thomas J. Methods for the synthesis of qualitative research: a critical review. BMC Med Res Methodol 2009; 9:59.

24. Hannes K, Lockwood C. Synthesizing qualitative research: Choosing the right approach. John Wiley \& Sons; 2011.

25. Tong A, Flemming K, McInnes E, Oliver S, Craig J. Enhancing transparency in reporting the synthesis of qualitative research: ENTREQ. BMC Med Res Methodol 2012; 12:181.

26. Disler RT, Green A, Luckett T et al. Experience of advanced chronic obstructive pulmonary disease: metasynthesis of qualitative research. J Pain Symptom Manage 2014; 48(6):11821199.

27. Smith AK, Fisher J, Schonberg MA et al. Am I doing the right thing? Provider perspectives on improving palliative care in the emergency department. Ann Emerg Med 2009; 54(1):86-93, 93.

28. Smith AK, Schonberg MA, Fisher J et al. Emergency department experiences of acutely symptomatic patients with terminal illness and their family caregivers. J Pain Symptom Manage 2010; 39(6):972-981.

29. Jelinek GA, Marck CH, Weiland TJ et al. Caught in the middle: tensions around the emergency department care of people with advanced cancer. Emerg Med Australas 2013; 25(2):154-160. 
30. Marck $\mathrm{CH}$, Weil J, Lane $\mathrm{H}$ et al. Care of the dying cancer patient in the emergency department: findings from a National survey of Australian emergency department clinicians. Intern Med J 2014; 44(4):362-368.

31. Jelinek GA, Boughey M, Marck $\mathrm{CH}$ et al. "Better pathways of care": suggested improvements to the emergency department management of people with advanced cancer. J Palliat Care 2014; 30(2):83-89.

32. Lane $\mathrm{H}$, Weil J, Jelinek $\mathrm{GA}$ et al. Ideal care and the realities of practice: interdisciplinary relationships in the management of advanced cancer patients in Australian emergency departments. Support Care Cancer 2014; 22(4):1029-1035.

33. Bailey C, Murphy R, Porock D. Trajectories of end-of-life care in the emergency department. Ann Emerg Med 2011; 57(4):362-369.

34. Chan GK. Trajectories of approaching death in the emergency department: clinician narratives of patient transitions to the end of life. J Pain Symptom Manage 2011; 42(6):864881.

35. Grudzen CR, Richardson LD, Hopper SS, Ortiz JM, Whang C, Morrison RS. Does palliative care have a future in the emergency department? Discussions with attending emergency physicians. J Pain Symptom Manage 2012; 43(1):1-9.

36. Stone SC, Mohanty S, Grudzen CR et al. Emergency medicine physicians' perspectives of providing palliative care in an emergency department. J Palliat Med 2011; 14(12):1333-1338.

37. Grudzen CR, Stone SC, Mohanty SA et al. "I want to be taking my own last breath": patients' reflections on illness when presenting to the emergency department at the end of life. J Palliat Med 2011; 14(3):293-296.

38. Browne S, Macdonald S, May CR, Macleod U, Mair FS. Patient, carer and professional perspectives on barriers and facilitators to quality care in advanced heart failure. PLoS One 2014; 9(3):e93288.

39. Tarzian AJ. Caring for dying patients who have air hunger. J Nurs Scholarsh 2000; 32(2):137143.

40. Shearer FM, Rogers IR, Monterosso L, Ross-Adjie G, Rogers JR. Understanding emergency department staff needs and perceptions in the provision of palliative care. Emerg Med Australas 2014; 26(3):249-255.

41. Payne SA, Dean SJ, Kalus C. A comparative study of death anxiety in hospice and emergency nurses. J Adv Nurs 1998; 28(4):700-706.

42. Stephens $\mathrm{C}$, Halifax E, Bui $\mathrm{N}$ et al. Provider Perspectives on the Influence of Family on Nursing Home Resident Transfers to the Emergency Department: Crises at the End of Life. Curr Gerontol Geriatr Res 2015; 2015:893062.

43. Weinick RM, Wilcox SR, Park ER, Griffey RT, Weissman JS. Use of advance directives for nursing home residents in the emergency department. Am J Hosp Palliat Care 2008; 25(3):179-183. 
44. Henderson AC. Patient assessment in emergency medical services: complexity and uncertainty in street-level patient processing. J Health Hum Serv Adm 2013; 35(4):505-542.

45. Dixon J, King D, Matosevic T, Clark M, Knapp M. Equity of provision of palliative care in the UK; review of the evidence. 2015. Marie Curie, LSE. 30-10-2017.

Ref Type: Report

46. King N, Thomas K, Martin N, Bell D, Farrell S. 'Now nobody falls through the net': practitioners' perspectives on the Gold Standards Framework for community palliative care. Palliat Med 2005; 19(8):619-627.

47. Redfern E, Brown R, Vincent CA. Identifying vulnerabilities in communication in the emergency department. Emerg Med J 2009; 26(9):653-657.

48. Ferguson WJ, Candib LM. Culture, language, and the doctor-patient relationship. Fam Med 2002; 34(5):353-361.

49. Smith C, Hough L, Cheung CC et al. Coordinate My Care: a clinical service that coordinates care, giving patients choice and improving quality of life. BMJ Support Palliat Care 2012; 2(4):301-307.

50. Michelson KN, Steinhorn DM. Pediatric End-of-Life Issues and Palliative Care. Clin Pediatr Emerg Med 2007; 8(3):212-219.

51. Hough CL, Hudson LD, Salud A, Lahey T, Curtis JR. Death rounds: end-of-life discussions among medical residents in the intensive care unit. J Crit Care 2005; 20(1):20-25.

52. Nelson JE, Angus DC, Weissfeld LA et al. End-of-life care for the critically ill: A national intensive care unit survey. Crit Care Med 2006; 34(10):2547-2553.

53. Nelson JE, Mathews KS, Weissman DE et al. Integration of palliative care in the context of rapid response: a report from the Improving Palliative Care in the ICU advisory board. Chest 2015; 147(2):560-569.

54. Gisondi MA. A case for education in palliative and end-of-life care in emergency medicine. Acad Emerg Med 2009; 16(2):181-183.

55. Johnson MJ. Breaking the deadlock. British Journal of Cardiology 2015; 22:10-11.

56. Fallowfield L, Lipkin M, Hall A. Teaching senior oncologists communication skills: results from phase I of a comprehensive longitudinal program in the United Kingdom. J Clin Oncol 1998; 16(5):1961-1968.

57. Fallowfield L, Jenkins V, Farewell V, Saul J, Duffy A, Eves R. Efficacy of a Cancer Research UK communication skills training model for oncologists: a randomised controlled trial. Lancet 2002; 359(9307):650-656.

58. Meier DE, Beresford L. Fast response is key to partnering with the emergency department. J Palliat Med 2007; 10(3):641-645.

59. Waugh DG. Palliative care project in the emergency department. J Palliat Med 2010; 13(8):936. 
60. Stone SC, Mohanty SA, Gruzden C, Lorenz KA, Asch SM. Emergency department research in palliative care: challenges in recruitment. J Palliat Med 2009; 12(10):867-868.

61. Boland J, Currow DC, Wilcock A et al. A systematic review of strategies used to increase recruitment of people with cancer or organ failure into clinical trials: implications for palliative care research. J Pain Symptom Manage 2015; 49(4):762-772. 
ABSTRACT

Background: Despite a fast-paced environment, the emergency clinician has a duty to meet the palliative patient's needs. Despite suggested models and interventions, this remains challenging in practice.

Aim: To increase understanding of these challenges by exploring the experience of palliative care patients and their families and informal carers attending the emergency department, and of the clinicians caring for them.

Design: Qualitative systematic literature review and thematic synthesis. Search terms related to the population (palliative care patients, family carers, clinicians), exposure (the emergency department) and outcome (experience). The search was international but restricted to English, and used a qualitative filter. Title, abstracts and retrieved full texts were reviewed independently by two reviewers against predefined inclusion criteria arbitrated by a third reviewer. Studies were appraised for quality but not excluded on that basis.

Data Sources: MEDLINE [1946-], Embase[1947-], CINAHL [1981-] and PsycINFO [1987-] with a bibliography search.

Results: 19 papers of 16 studies were included from Australia $(n=5)$, the United Kingdom $(n=5)$ and United States $(n=9)$ representing 482 clinical staff involved in the emergency department (doctors, nurses, paramedics, social workers, technicians), 61 patients and 36 carers. Nine descriptive themes formed three analytic themes: "Environment and Purpose"; "Systems of Care and Interdisciplinary Working" and "Education and Training".

Conclusions: Provision of emergency palliative care is a necessary purpose of the emergency department. Failure to recognise this, gain the necessary skills, or change the systems needed for an environment better suited to its delivery perpetuates poor implementation of care in this environment.

Key words: emergency department; emergency care; palliative; experience; qualitative 


\section{What is already known about the topic?}

- The emergency department is a chaotic and fast-paced environment with a primary aim of rapid assessment and acute clinical care.

- However, the emergency physician also has a duty to meet the palliative patient's needs for care, comfort, and compassion; delivery of these goals is variably met.

- Models of palliative care in the emergency department are described, but implementation is poor

\section{What this paper adds}

- Multiple level issues contribute to suboptimal care for palliative care patients and their families in the ED; system and organisational, clinician education and training, interdisciplinary and cross-setting working and clinician attitudes focussing on acute restorative care rather than palliation.

- These findings provide explanation for the persisting poor implementation of best practice

\section{Implications for practice, theory or policy}

- Problems at all levels need to be addressed, but the foundational need is that care of palliative patients is recognised at all levels as a legitimate purpose of the ED. 


\section{INTRODUCTION}

Emergency departments (EDs) receive patients with a wide range of clinical conditions from those with acute trauma, through to those with terminal illness. ${ }^{1}$ The primary focus of the ED is on rapid assessment and acute clinical care with a view to transfer of patients to appropriate clinical contexts in a timely and efficient manner. ${ }^{2}$

Palliative care is defined by the World Health Organisation as an approach which "improves the quality of life of patients and their families ... with life-threatening illness, through the ... impeccable assessment and treatment of pain and other problems" and is applicable alongside treatments intended to prolong life. ${ }^{3}$ Such an approach can be difficult during an initial attendance at the ED, especially where crucial information about the patient's clinical history or management plan may not be readily available. Furthermore, the fast-paced and sometimes even chaotic context of the ED does not provide an easy environment for advance care planning, communication and provision of comfort measures. ${ }^{4}$

The need for attention to symptoms and other palliative care needs in the ED cannot be dismissed as a rarity or completely unavoidable. ${ }^{5}$ For example, breathlessness is a common symptom in people with chronic cardio-respiratory conditions, which typically worsens with disease progression. ${ }^{6,7}$ Distressing respiratory symptoms is one of the most common reasons for palliative care patients to attend the ED. ${ }^{8}$ Acute-on-chronic breathlessness is one of the most frightening experiences for patients and their carers and is associated with ED attendance. ${ }^{9,10}$ Nevertheless, a significant proportion of those attending due to acute-on-chronic breathlessness are discharged the same day, ${ }^{9}$ suggesting that their attendance was not primarily driven by acute deterioration of the underlying pathology. The needs of these patients could perhaps be better met by management co-ordinated in the community. ${ }^{9}$ Attendance may, of course, be appropriate and, whether admitted or not, for people living with chronic breathlessness ${ }^{11}$ an attendance at the ED where exclusion of a diseaserelated exacerbation is the sole focus of the encounter may miss an opportunity for their palliative care to be optimised and to prevent re-attendance.

In 2008, the American College of Emergency Physicians recognised that despite a chaotic and fastpaced environment, the emergency physician has a duty to meet the palliative patient's needs for care, comfort, and compassion. ${ }^{12}$ Observational study has highlighted some of the reasons why people with advanced cancer present to the ED, ${ }^{13}$ and various models of incorporating palliative care into the ED have been described, ${ }_{14}^{14}$ but with little evidence of patient benefit. ${ }^{15}$ However, this remains a challenge in practice. ${ }^{4,16-18} \mathrm{~A}$ broad review of 160 papers described a number of relevant problems: uncertainty, issues around quality of life, cost, the relationship between ED and other health services, quality of hospital care and ethical and social issues. ${ }^{19}$

Qualitative research can offer insights into how patients, carers and healthcare professionals experience the provision of palliative care in the ED, help explain described problems and point to solutions. The aim of this qualitative systematic literature review and thematic synthesis was to raise awareness of the experience of a broader population of palliative care patients and their families 
and carers attending the ED, together with the insights of clinicians caring for them thereby increasing understanding why implementation of good practice remains difficult.

\section{METHOD}

The search strategy was pre-planned. The following electronic databases (MEDLINE [1946-], Embase [1947-], CINAHL [1981-] and PsycINFO [1987-]) were searched in January 2016 for published journal articles in English using Flemming's qualitative filter. ${ }^{20}$ The electronic database search was supplemented by a manual search of citations from key existing reviews on similar subject matter. The search strategy and search terms are shown in the online eTable 1 and modified for each database. Terms were developed to address the population (palliative care), exposure (the ED) an outcome (experience). Titles and abstracts were reviewed by two independent reviewers (E.C. and Z.S.) against predefined inclusion criteria (Table 1). Discrepancies were resolved by discussion and a third independent reviewer (M.J.J.). This process was then repeated reviewing the full texts. All studies identified for inclusion were appraised by E.C. for quality (including congruity, influence of the researcher, representation of participant voice) using the QARI Critical Appraisal Checklist for Interpretive and Critical Research. ${ }^{21}$ Studies were not excluded on the basis of quality, but quality was taken into account with regard to the interpretation of findings.

Table 1. Eligibility criteria

\begin{tabular}{|c|c|}
\hline Inclusion Criteria: & Exclusion Criteria: \\
\hline $\begin{array}{l}\text { - English language full reports } \\
\text { - Design: primary qualitative empirical } \\
\text { research } \\
\text { - Population: adult* palliative care patients } \\
\text { attending the emergency department, carers } \\
\text { or clinicians, mixed adult/children } \\
\text { populations where data from adults could be } \\
\text { extracted } \\
\text { - Outcome: studies addressing any aspect of } \\
\text { participants' experience }\end{array}$ & $\begin{array}{l}\text { - Design: } \\
\quad \text { studies labelled qualitative but not } \\
\text { using qualitative methodology (e.g. } \\
\text { studies using qualitative categorical } \\
\text { variables or structured interviews) } \\
\circ \text { quantitative research } \\
\circ \quad \text { case reports (unless recognised } \\
\quad \text { qualitative methodology) } \\
\circ \quad \text { opinion pieces } \\
\text { - Population: studies including only paediatric } \\
\text { patients }\end{array}$ \\
\hline
\end{tabular}

Data were extracted from included papers by E.C. using a bespoke data extraction form. Contextual information about each study was extracted, together with all primary data (direct and paraphrased participants' quotations) where available.

Data were synthesized using thematic synthesis ${ }^{22}$ thereby allowing the context of each study to be taken into account in the production of a generalisable whole. ${ }^{23}$ Thematic synthesis was chosen because it uses a realist approach (external reality can be adequately represented) consistent with the epistemological position held by the researchers. ${ }^{24}$ In view of the heterogeneity of the included studies in terms of their research aims and populations studied, meta-ethnography was not suitable, and only primary and paraphrased quotes from participants were extracted from each paper and 
then coded. EC read the papers and added codes by hand using Atlas.ti version 7, Scientific Software Development $\mathrm{GmbH}$, Berlin, to manage the data. The synthesis was performed in three stages: the first stage was line-by-line coding searching for concepts in the primary research findings (direct and paraphrased quotations) of each study on the experience of patients with palliative care needs attending the ED (E.C). Secondly, these codes were then refined, and through an inductive reasoning process organised into descriptive themes. Thirdly, supported by A.H., the analytical themes emerged following a process of reflection on the descriptive themes involving discussion and interpretation (A.H, E.C., M.J. and W.T) to provide a broad understanding of the experience of palliative care in the ED. E.C. and W.T. are ED clinicians, A.H. is a health researcher and M.J. is a professor of palliative medicine. All will have brought their previous experiences to bear in interpretation, but transparency of the method, independent selection of and extraction from primary studies and group discussion provides rigour to the review and synthesis process. The synthesis is reported in accordance with the Enhancing Transparency in Reporting the synthesis of Qualitative research (ENTREQ) guidance. ${ }^{25}$

\section{RESULTS}

\section{Selected studies:}

Literature searching retrieved eligible 19 papers covering 16 studies from Australia $(n=5)$, the United Kingdom $(n=5)$ and United States $(n=9)$ representing 482 clinical staff, 61 patients and 36 carers (see Figure 1). A summary of the included articles is provided in Table 2 but most studies included clinicians only $(n=11)$. The remaining 8 studies had a variable mix of patients with family carers and/or clinicians. 

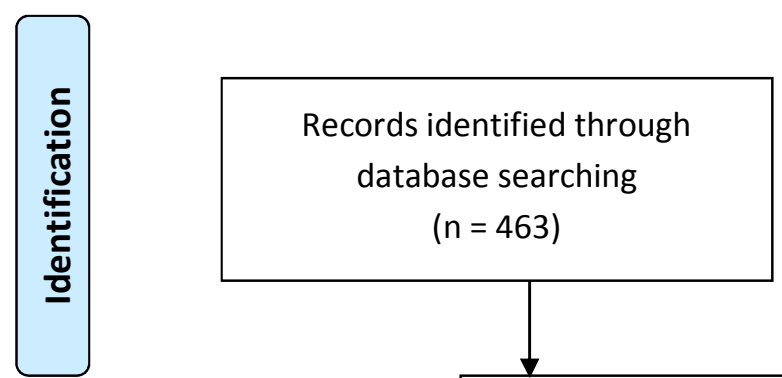

Additional records identified through other sources

Records after duplicates removed $(n=5)$

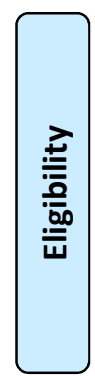

$$
(n=336)
$$
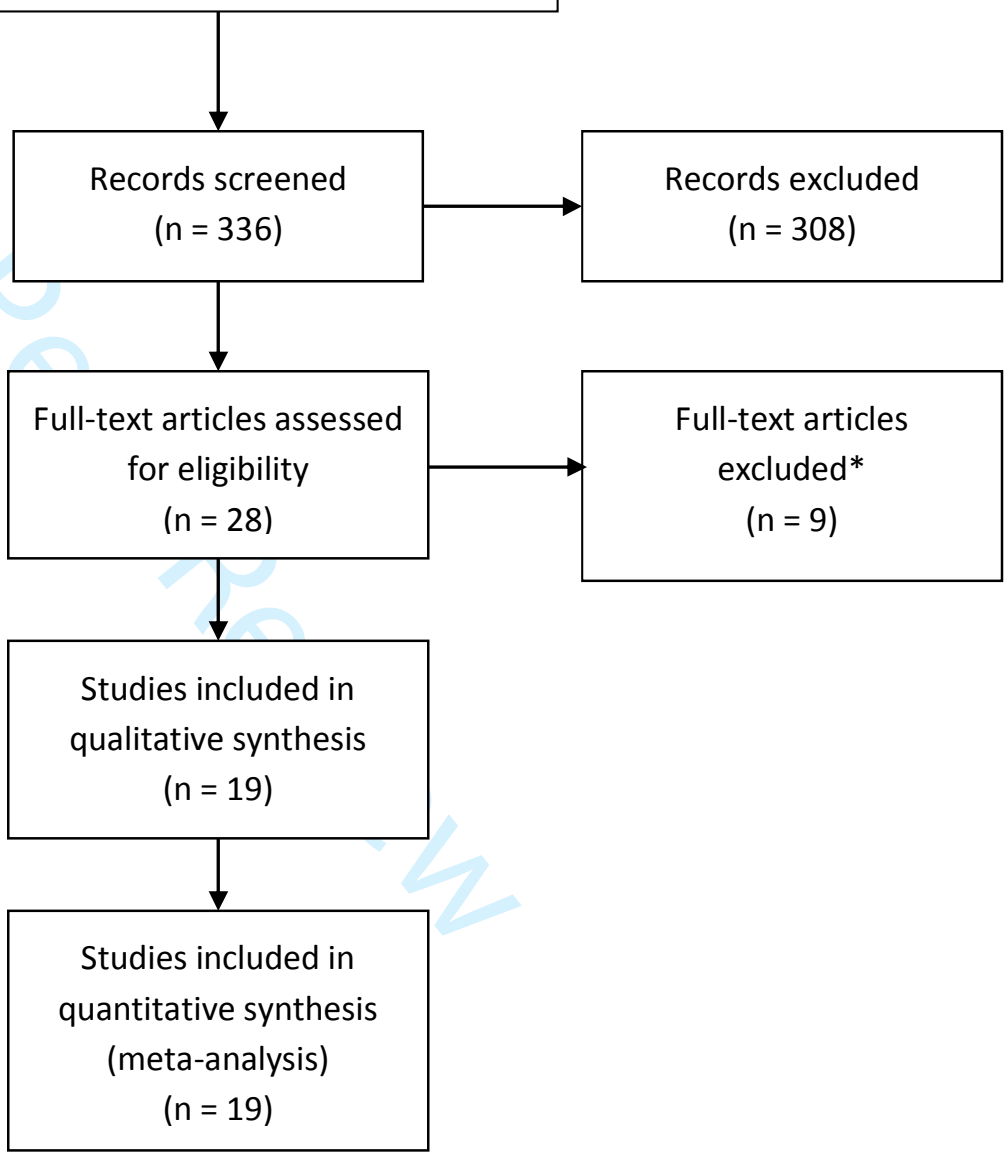

Figure 1. PRISMA flow chart. *Papers were excluded if they did not use qualitative methods $(n=5)$, did not report on emergency department specific situations $(n=2)$ or only reported on acute or traumatic deaths or had no reference to palliative care $(n=2)$

\section{<<insert Table 2 about here〉>}




\section{Quality of included studies}

Most studies presented clear aims and objectives, described the qualitative methods used and the techniques for data collection and had congruity between objectives, methods and interpretation of results (see eTable 2 QARI Appraisal). They also appeared to adequately represent the views of participants throughout the analysis. In keeping with qualitative research methods, sample sizes were small, but adequate for the method described. The purpose of qualitative research is not to produce generalizable results and this was discussed by all authors with regards to the limitations of the study limited capacity for generalizability as is common in such qualitative research. ${ }^{26}$

\section{Thematic synthesis}

Coding of these 19 articles revealed 31 free text codes which were divided into nine descriptive themes. These themes were then condensed further into three analytical themes that described the most prominent aspects of the experience of palliative care patients, relatives and healthcare providers in the ED. These three analytic themes form the basis of the discussion below. They are: "Environment and Purpose"; "Systems of Care and Interdisciplinary Working" and "Education and Training" (Table 3).

Table 3. Relationships between themes

\begin{tabular}{|c|c|c|}
\hline Analytical themes & Themes & Codes \\
\hline \multirow[t]{2}{*}{$\begin{array}{l}\text { Environment and } \\
\text { purpose }\end{array}$} & $\begin{array}{l}\text { Environmental } \\
\text { factors }\end{array}$ & $\begin{array}{l}\text { - } \text { Noisy environment } \\
\text { - } \text { Long waiting times } \\
\text { - } \text { Time pressures } \\
\text { - } \text { Resource limitation } \\
\text { - } \text { Low prioritisation } \\
\text { - } \text { Regregation and isolation of the dying } \\
\text { - } \text { ED not an ideal place to die }\end{array}$ \\
\hline & Providing care & $\begin{array}{l}\text { - } \text { Role of palliative care } \\
\text { - Symptom control } \\
\text { - Clinicians' comfort in providing care } \\
\text { - Building relationships with patients } \\
\text { - Caring for relatives }\end{array}$ \\
\hline \multirow{4}{*}{$\begin{array}{l}\text { Systems of care } \\
\quad \text { and } \\
\text { interdisciplinary } \\
\quad \text { working }\end{array}$} & Communication & $\begin{array}{l}\text { - } \text { Breaking bad news } \\
\text { - } \quad \text { Quality of communication } \\
\text { - Need for clear communication }\end{array}$ \\
\hline & $\begin{array}{l}\text { Interdisciplinary } \\
\text { working }\end{array}$ & $\begin{array}{l}\text { - } \text { Communication between specialties } \\
\text { - Transfer of information } \\
\text { - Appropriate clinicians initiating discussion }\end{array}$ \\
\hline & Decision making & $\begin{array}{l}\text { - Patient involvement } \\
\text { - Influence of relatives }\end{array}$ \\
\hline & Accessing care & $\begin{array}{l}\text { - Relatives instigating escalation of care } \\
\text { - Lack of access to community palliative care } \\
\text { - } \quad \text { Lack of direct access to secondary care } \\
\text { - Palliative care consultations in the ED }\end{array}$ \\
\hline Education and & Education & - Need for education \\
\hline
\end{tabular}


"When you're being forced to wait for so long and in pain it feels like the opposite of caring."

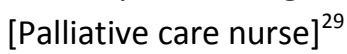

With the aim of providing privacy and space for patients and relatives, dying patients were frequently separated from other patients in the ED in corner rooms and relatives' rooms and then transferred out of the department as quickly as possible. ${ }^{18}$ The encouragement of communication between patients and their relatives was seen to facilitate more appropriate treatment options and goals of care. ${ }^{4,27,31}$ However, some EDs had little space for family members to remain with their relative at a distressing time or for confidential and sensitive discussions surrounding goals of care. ${ }^{29}$

Although most ED clinicians recognised and accepted that care of the dying was a reasonable demand and could be rewarding, they considered the ED to be an inappropriate place to die ${ }^{30}$ and a suboptimal environment for people with advanced cancer. ${ }^{29}$ This led to a tension between the belief that ED clinicians should be able to provide palliative care and the concern that they were unable to provide this care well despite their best efforts. $^{32}$

"Helping someone die in comfort and dignity . . . is some of the most rewarding clinical experiences I have. I feel I have not been able to completely provide the care, respect and dignity for the patient who dies within the ED." [Healthcare professional] ${ }^{30}$ 
ED clinicians agreed that they should provide symptomatic relief for acute problems experienced by those with advanced and terminal disease. However, concerns about ineffective symptom management and poor communication were identified as a significant cause of dissatisfaction with the patients' ED experience. ${ }^{18,28,33-38}$ In addition, ED clinicians vary in confidence in their palliative care skills. ${ }^{27,30,39}$ Being aware of and keeping the patient's wishes central to decision making was felt to be key to providing a "good death" in the ED. ${ }^{18,40}$ Building relationships with patients ${ }^{35}$ was seen as particularly challenging, but recognised as key to good quality of care especially when advocating for the patient at a time of crisis ${ }^{17}$ along with caring for accompanying relatives. ${ }^{33,41}$

Systems of care and interdisciplinary working (eTable 4)

ED users emphasised the need for clear communication ${ }^{17,28,36}$ noting problems when this did not occur. ${ }^{33}$ Clinicians found it difficult to break bad news to end-of-life patients, exacerbated by the perceived pressures to clear space for the next ED patient. ${ }^{18}$ Barriers to sensitive discussions included language barriers, differing cultural and/or spiritual beliefs and limited health literacy. ${ }^{36}$

"We found a great lack of communication to be quite honest because they [the ED staff] were very busy ... so the information wasn't very forthcoming. It wasn't until Dad got here [the Specialist Palliative Care Unit] that answers started to become apparent. I think from our point of view, purely from the frustration as a family member, I wanted to know what was going off. The lack of information was infuriating." [Relative] ${ }^{33}$

Communication among clinicians and between services was seen as important but fraught with difficulties, compromised by other demands on time. ${ }^{32}$ Poor transfer of information between those involved in a patient's care and a lack of clinical information about previously negotiated goals of care led to active, and potentially inappropriate invasive, treatment by default. ${ }^{30}$ However, ED clinicians frequently reported concerns that discussions with regards to ceilings of medical treatment had not been undertaken prior to attendance at the ED, even for patients with apparent progressing disease. ${ }^{27,32}$ Clinicians felt particularly uneasy where the patient appeared unaware of their diagnosis or stage of disease. ${ }^{35}$ It was felt that such important discussions should occur with a doctor who knew the patient well. ${ }^{32}$

"Part of the problem involves being able to communicate effectively with people who know the patients better - their primary care providers, their oncologists - but who aren't there at the $[E D]$ at the time the patient comes in." [ED physician] ${ }^{27}$

Unawareness of the severity of illness extended to relatives, who were seen to have great influence on the care provided in ED and often swayed the decision whether or not to provide palliative or curative care measures. This challenged physicians as it could be difficult to meet the needs of both the patient and the family, especially when the family expected heroic measures. ${ }^{36}$ This conflict between patients, relatives and clinicians often caused moral distress. ${ }^{34}$ This distress was reported in conflict between the patient's previously expressed wishes and their family ${ }^{42}$ and between clinicians due to the perceived unrealistic expectations of some inpatient teams. ${ }^{30}$ 


\begin{abstract}
"The patient came with a comfort measures only/do-not-hospitalize piece of paperworkvery demented patient, couldn't even speak in complete sentences, couldn't process anything that we said, and that was her baseline according to all of the records that we received. The family member reversed everything while I was on the phone, saying 'I do want her hospitalized, and I want you to do everything possible." [ED physician] ${ }^{27}$
\end{abstract}

Families also often prompted patients to access emergency care ${ }^{42}$ and despite previous discussions and education with regards to the patient's condition and prognosis. ${ }^{34}$ The patient was often disgruntled at having been taken to ED once their condition improved and they regained capacity. ${ }^{28}$

In general, patients described ED attendance as unwanted or a last resort, but an unavoidable consequence of lack of access to services, including palliative care expertise, in the community, especially when crises occurred out-of-hours ${ }^{36}$ or in secondary specialist care settings. ${ }^{29}$ This was seen by ED staff as a failure of clinicians' long term care of patients ${ }^{32}$ and that the presenting symptoms could have been pre-empted ${ }^{29}$ or the patient transferred to a suitable care setting with access to expertise in palliative care. ${ }^{42}$

"Optimal care for advanced cancer patients would involve remaining in the community and avoiding ED attendance and hospital admission. ED attendance was widely seen as a failure and the ED a less than ideal environment for patients with advanced cancer. I think we go to great lengths to avoid attendances to emergency departments unless we really have to." [PC clinician $]^{32}$

The inadequacy of current systems of care leading to ED attendances for patients with palliative care needs was highlighted in several studies. Suggestions included a "palliative care hotline" to improve access to useful clinical and organisational information or access to specially trained nurses able to be called on as required. ${ }^{27}$ Eligibility criteria for palliative care consultation would help standardise the use of palliative care services and increase palliative care visibility in the ED. ${ }^{36}$ Specialist palliative care consults in ED were particularly welcomed by patients and relatives previously familiar with the palliative care team as either an inpatient or outpatient. ${ }^{28}$

\title{
Education and training (eTable 5)
}

As well as requesting palliative care consultations, ED clinicians were keen to develop their own skills in palliative care, ${ }^{35}$ symptom control ${ }^{29}$ and communication skills. ${ }^{27,43} \mathrm{~A}$ lack of palliative care training within the emergency medicine curriculum was identified as a barrier to the provision of palliative care ${ }^{27}$ and addressing this with education of both medical and nursing ED staff was seen as a way to improve care. ${ }^{33,36}$ The collaboration between ED and palliative care teams was highlighted as a potential way to overcome these educational shortfalls. ${ }^{35}$ The use of palliative care nurse champions $31,35,42$ and the provision of educational materials, presentations and courses tailored to the needs of ED staff were suggested as ways to achieve this. ${ }^{36}$ 
"Palliative pain control is a very specialised area. I think most EDs are quite blunt with how they manage pain, and certainly the options that are considered by palliative care specialist may not even be known about by a lot of ED doctors." [ED consultant] ${ }^{29}$

Particular gaps in knowledge and skills included decisions about antibiotic or intravenous fluids in the context of comfort care, ${ }^{27}$ the medico-legal aspects of withholding futile interventions ${ }^{30,35}$ and the interpretation and application of advanced directives (ADs). ${ }^{27,30,43}$ These concerns affected both the ED providers and formal carers (particularly in nursing homes) who often chose to transfer patients to the ED against their clinical judgement for fear of repercussions with the family or litigation. $^{42}$

"People have a phobia, they think that if they have an AD we're going to kill them or something or use them for organ donation." [Healthcare professional] ${ }^{43}$

Promotion of ADs was considered important in encouraging patients to plan for foreseeable events in their disease progression. ${ }^{16}$ Communication skills were seen as another gap, ${ }^{44}$ and ensuring patients and family members were aware of the likely progression of illness was felt to minimise ED attendances and also improve quality of care. ${ }^{29}$ They identified recognition of poor prognosis as a key educational need including the significance of symptoms as a trigger for transfer to the ED, ${ }^{27,28}$ carer burden $^{42}$ and the role of a hospice. ${ }^{34}$

\section{DISCUSSION}

This systematic review of literature and thematic synthesis described the experiences of palliative care patients, relatives and clinicians in the ED and the potential conflicts between the goals of emergency care and palliative care. The synthesis of multiple, independent studies provided three overarching themes to illustrate areas of tension that affected the successful delivery or experience of care: environment and purpose, system of care and interdisciplinary working, and education and training.

Although great effort has been put into improving access to palliative care ${ }^{45}$ and its provision in the community, ${ }^{46}$ the findings of this review suggest some palliative care patients will always need to present to the ED. There was clear congruence between the role of the ED and palliative care in managing the physical symptoms of palliative patients at times of crisis, reflected by the wide acceptance of ED staff to provide symptomatic relief. However, there was conflict of opinion with regards to how well this is currently performed and what level of skill should be expected of ED staff. Although ED clinicians should be equipped to deal with emergency palliative care issues - poorly controlled symptoms, acute conditions such as spinal cord compression and acute unpredictable deteriorations - the task of advance care planning was felt to sit better with clinicians with an established relationship with the patient. The brief nature of the healthcare professional-patient relationship in the ED was a key issue. Barriers to high quality communication echoed those identified in existing literature: the fast pace and limited resources of the ED, ${ }^{47}$ language barriers and 
cultural or religious differences. ${ }^{48}$ Inexperience left ED physicians uncertain how to raise difficult issues surrounding future care.

System barriers to the transfer of information were a recurrent issue that could be addressed by services such as "coordinate my care". ${ }^{49}$ ED clinicians" access to a personalised plan of care would also facilitate communication with relatives to overcome conflicts between their wishes and those of the patient and between conflicting wishes of multiple relatives. Provision of empathetic palliative care can cause emotional and moral distress for clinicians. Systems of support at an institutional level such as counselling and case discussions have been called for in other specialties (e.g. paediatrics, ${ }^{50}$ intensive care ${ }^{51,52}$ and rapid response teams ${ }^{53}$ ) caught in the tension between saving lives and caring for the dying which may be comparable. ${ }^{4}$

Although attendance at the ED is often a "last resort", it is currently often unavoidable, in particular when clinical or emotional support is required out-of-hours. Access to emergency community-based generalist and specialist palliative care remains patchy.

Consistent with other calls for education about end of life care for emergency clinicians, ${ }^{54}$ training should address the interdisciplinary educational shortfalls at both undergraduate and postgraduate levels - including senior clinicians. ${ }^{55}$ Involvement of palliative care clinicians for patients with complex needs will facilitate learning and also provide support for the emergency teams.

Education should extend beyond clinicians, to include patients and relatives. Important areas include likely disease progression, facilities to manage symptoms at home, advance care planning and the role of the hospice. Education and specialist support in dealing with the emotional challenge of providing care at home may also be required.

\section{Implications for clinical practice and future research}

A formal acceptance by clinicians in the ED that their role is not only "heroic" ${ }^{36}$ or "lifesaving" 17 , but also to provide care for those beyond rescue is necessary. The inclusion of palliative care competencies in the curricula for specialist medical trainees and training for ED nurses would better equip the staff with skills and emphasise that palliative care is part of their job. Advanced communication skills training should be as much a key part of training for ED clinicians as it is for primary care, oncology and palliative care clinicians. Senior clinicians should be included in training to ensure they provide leadership in this culture change..$^{55-57}$

Such change would be supported by a closer interdisciplinary collaboration between existing palliative, primary and emergency care specialties and allow both emergency and palliative care providers to negotiate their specific roles in the provision of care and access training about symptom management from the palliative care team. Usual care team clinicians (both hospital and primary care) should be aware of the impact of abdicating responsibility with regard to advance care planning and access to the patient's clinical record, including such discussions, should be made available to ED clinicians.

From these data, models whereby ED clinicians perceive palliative care as the specialist palliative care team's responsibility, with their only role being identification of "the palliative patient" may risk an unsustainable and resource intensive load on specialist services, ${ }^{58}$ or failure to "see" the patient for which ED clinicians perceive they have inadequate skills. However, changes which include the 
development of palliative care "champions" amongst the ED workforce ${ }^{59}$ in partnership with specialist providers, with an expectation that all ED staff gain basic competencies in palliative care, alongside practical, low cost adaptations (private space, curtains, chairs for family) would appear possible, welcomed by ED clinicians and helpful for patients and families. Further research into the best models of service configuration and delivery, including workforce education, training and communication requirements will be difficult, ${ }^{60}$ but not insurmoutable ${ }^{61}$ and is urgently needed ${ }^{14}$

\begin{abstract}
Limitations of this study
Due to team resource limitations and the challenges of maintaining code meaning in translation, this study was limited to English-language papers. Also, even with the best search strategy, key papers may have been omitted. Despite these limitations, significant findings have been portrayed that could have a positive impact on the experience of palliative care patients attending the ED.
\end{abstract}

\title{
CONCLUSIONS
}

Some palliative care patients will need the ED. Issues regarding the environment and purpose, system of care and interdisciplinary working, and education and training influence the delivery and experience of care. Only when the importance of palliative care in the ED is recognised by both those that work there and those in palliative care and the necessary skills gained, can systems begin to change to enable an environment better suited to its delivery. Failure to do so will perpetuate poor implementation of palliative care in this environment.

\section{DISCLOSURES AND ACKNOWLEDGEMENTS}

\section{Declarations}

EC conceived the research question; WT, EC, MJJ, AH developed the protocol; EC conducted the search; EC, ZS assessed for inclusion; AH provided methodological guidance; EC, AH, WT, MJJ, PT analysed and/or interpreted the data; EC wrote the first draft, all authors contributed to drafts and approved the final version.

\section{Funding}

No funding was received for this study.

Declaration of conflicts of interest.

The authors declare no conflicts of interest

Research ethics and patient consent. 


\begin{abstract}
Not applicable
Data management and sharing
\end{abstract}

The search strategy and extracted data are presented and thus available. 


\section{REFERENCE LISTReference List}

1. Chan GK. End-of-life models and emergency department care. Acad Emerg Med 2004; 11(1):79-86.

2. Lecky F, Benger J, Mason S, Cameron P, Walsh C. The International Federation for Emergency Medicine framework for quality and safety in the emergency department. Emerg Med J 2014; 31(11):926-929.

3. WHO Definition of Palliative Care. http://www.who.int/cancer/palliative/definition/en/. 2013. 28-7-2013.

Ref Type: Electronic Citation

4. Savory EA, Marco CA. End-of-life issues in the acute and critically ill patient. Scand J Trauma Resusc Emerg Med 2009; 17:21.

5. Green E, Gott M. Palliative care in the emergency department: avoidable or appropriate? $\mathrm{Br}$ J Hosp Med (Lond) 2016; 77(12):674-675.

6. Currow DC, Smith J, Davidson PM, Newton PJ, Agar MR, Abernethy AP. Do the trajectories of dyspnea differ in prevalence and intensity by diagnosis at the end of life? A consecutive cohort study. J Pain Symptom Manage 2010; 39(4):680-690.

7. Johnson MJ, Bland JM, Gahbauer EA et al. Breathlessness in Elderly Adults During the Last Year of Life Sufficient to Restrict Activity: Prevalence, Pattern, and Associated Factors. J Am Geriatr Soc 2016; 64(1):73-80.

8. Green E, Gott M, Wong J. Why do adults with palliative care needs present to the emergency department? A narrative review of the literature. Progress in Palliative Care 2016; 24(4):195203.

9. Hutchinson A, Pickering A, Williams P, Bland JM, Johnson MJ. Breathlessness and presentation to the emergency department: a survey and clinical record review. BMC Pulm Med 2017; 17(1):53.

10. Niska R, Bhuiya F, Xu J. National Hospital Ambulatory Medical Care Survey: 2007 emergency department summary. Natl Health Stat Report 2010;(26):1-31.

11. Johnson MJ, Yorke J, Hansen-Flaschen J et al. Towards an expert consensus to delineate a clinical syndrome of chronic breathlessness. European Respiratory Journal 517; in press.

12. Ethical issues at the end of life. Ann Emerg Med 2008; 52(5):592.

13. Henson LA, Gao W, Higginson IJ et al. Emergency department attendance by patients with cancer in their last month of life: a systematic review and meta-analysis. J Clin Oncol 2015; 33(4):370-376.

14. Grudzen CR, Stone SC, Morrison RS. The palliative care model for emergency department patients with advanced illness. J Palliat Med 2011; 14(8):945-950. 
15. da Silva SD, Nunes CM, Gomes B. Effectiveness of Emergency Department Based Palliative Care for Adults with Advanced Disease: A Systematic Review. J Palliat Med 2016; 19(6):601609.

16. Bailey C, Murphy R, Porock D. Professional tears: developing emotional intelligence around death and dying in emergency work. J Clin Nurs 2011; 20(23-24):3364-3372.

17. Bailey CJ, Murphy R, Porock D. Dying cases in emergency places: caring for the dying in emergency departments. Soc Sci Med 2011; 73(9):1371-1377.

18. Decker K, Lee $\mathrm{S}$, Morphet J. The experiences of emergency nurses in providing end-of-life care to patients in the emergency department. Australas Emerg Nurs J 2015; 18(2):68-74.

19. Forero R, McDonnell G, Gallego B et al. A Literature Review on Care at the End-of-Life in the Emergency Department. Emerg Med Int 2012; 2012:486516.

20. Flemming $\mathrm{K}$, Briggs $\mathrm{M}$. Electronic searching to locate qualitative research: evaluation of three strategies. J Adv Nurs 2007; 57(1):95-100.

21. The Joanna Briggs Institute: Joanna Briggs Institute Reviewers.2008, The Joanna Briggs Institute, 2008. 2017.

Ref Type: Report

22. Thomas J, Harden A. Methods for the thematic synthesis of qualitative research in systematic reviews. BMC Med Res Methodol 2008; 8:45.

23. Barnett-Page $E$, Thomas J. Methods for the synthesis of qualitative research: a critical review. BMC Med Res Methodol 2009; 9:59.

24. Hannes K, Lockwood C. Synthesizing qualitative research: Choosing the right approach. John Wiley \& Sons; 2011.

25. Tong A, Flemming K, McInnes E, Oliver S, Craig J. Enhancing transparency in reporting the synthesis of qualitative research: ENTREQ. BMC Med Res Methodol 2012; 12:181.

26. Disler RT, Green A, Luckett $\mathrm{T}$ et al. Experience of advanced chronic obstructive pulmonary disease: metasynthesis of qualitative research. J Pain Symptom Manage 2014; 48(6):11821199.

27. Smith AK, Fisher J, Schonberg MA et al. Am I doing the right thing? Provider perspectives on improving palliative care in the emergency department. Ann Emerg Med 2009; 54(1):86-93, 93.

28. Smith AK, Schonberg MA, Fisher J et al. Emergency department experiences of acutely symptomatic patients with terminal illness and their family caregivers. J Pain Symptom Manage 2010; 39(6):972-981.

29. Jelinek GA, Marck $\mathrm{CH}$, Weiland TJ et al. Caught in the middle: tensions around the emergency department care of people with advanced cancer. Emerg Med Australas 2013; 25(2):154-160. 
30. Marck $\mathrm{CH}$, Weil J, Lane $\mathrm{H}$ et al. Care of the dying cancer patient in the emergency department: findings from a National survey of Australian emergency department clinicians. Intern Med J 2014; 44(4):362-368.

31. Jelinek GA, Boughey M, Marck $\mathrm{CH}$ et al. "Better pathways of care": suggested improvements to the emergency department management of people with advanced cancer. J Palliat Care 2014; 30(2):83-89.

32. Lane $H$, Weil J, Jelinek $G A$ et al. Ideal care and the realities of practice: interdisciplinary relationships in the management of advanced cancer patients in Australian emergency departments. Support Care Cancer 2014; 22(4):1029-1035.

33. Bailey C, Murphy R, Porock D. Trajectories of end-of-life care in the emergency department. Ann Emerg Med 2011; 57(4):362-369.

34. Chan GK. Trajectories of approaching death in the emergency department: clinician narratives of patient transitions to the end of life. J Pain Symptom Manage 2011; 42(6):864881.

35. Grudzen CR, Richardson LD, Hopper SS, Ortiz JM, Whang C, Morrison RS. Does palliative care have a future in the emergency department? Discussions with attending emergency physicians. J Pain Symptom Manage 2012; 43(1):1-9.

36. Stone SC, Mohanty S, Grudzen CR et al. Emergency medicine physicians' perspectives of providing palliative care in an emergency department. J Palliat Med 2011; 14(12):1333-1338.

37. Grudzen CR, Stone SC, Mohanty SA et al. "I want to be taking my own last breath": patients' reflections on illness when presenting to the emergency department at the end of life. J Palliat Med 2011; 14(3):293-296.

38. Browne S, Macdonald S, May CR, Macleod U, Mair FS. Patient, carer and professional perspectives on barriers and facilitators to quality care in advanced heart failure. PLoS One 2014; 9(3):e93288.

39. Tarzian AJ. Caring for dying patients who have air hunger. J Nurs Scholarsh 2000; 32(2):137143.

40. Shearer FM, Rogers IR, Monterosso L, Ross-Adjie G, Rogers JR. Understanding emergency department staff needs and perceptions in the provision of palliative care. Emerg Med Australas 2014; 26(3):249-255.

41. Payne SA, Dean SJ, Kalus C. A comparative study of death anxiety in hospice and emergency nurses. J Adv Nurs 1998; 28(4):700-706.

42. Stephens $\mathrm{C}$, Halifax E, Bui N et al. Provider Perspectives on the Influence of Family on Nursing Home Resident Transfers to the Emergency Department: Crises at the End of Life. Curr Gerontol Geriatr Res 2015; 2015:893062.

43. Weinick RM, Wilcox SR, Park ER, Griffey RT, Weissman JS. Use of advance directives for nursing home residents in the emergency department. Am J Hosp Palliat Care 2008; 25(3):179-183. 
44. Henderson AC. Patient assessment in emergency medical services: complexity and uncertainty in street-level patient processing. J Health Hum Serv Adm 2013; 35(4):505-542.

45. Dixon J, King D, Matosevic T, Clark M, Knapp M. Equity of provision of palliative care in the UK; review of the evidence. 2015. Marie Curie, LSE. 30-10-2017.

Ref Type: Report

46. King N, Thomas K, Martin N, Bell D, Farrell S. 'Now nobody falls through the net': practitioners' perspectives on the Gold Standards Framework for community palliative care. Palliat Med 2005; 19(8):619-627.

47. Redfern $E$, Brown $R$, Vincent $C A$. Identifying vulnerabilities in communication in the emergency department. Emerg Med J 2009; 26(9):653-657.

48. Ferguson WJ, Candib LM. Culture, language, and the doctor-patient relationship. Fam Med 2002; 34(5):353-361.

49. Smith C, Hough L, Cheung CC et al. Coordinate My Care: a clinical service that coordinates care, giving patients choice and improving quality of life. BMJ Support Palliat Care 2012; 2(4):301-307.

50. Michelson KN, Steinhorn DM. Pediatric End-of-Life Issues and Palliative Care. Clin Pediatr Emerg Med 2007; 8(3):212-219.

51. Hough CL, Hudson LD, Salud A, Lahey T, Curtis JR. Death rounds: end-of-life discussions among medical residents in the intensive care unit. J Crit Care 2005; 20(1):20-25.

52. Nelson JE, Angus DC, Weissfeld LA et al. End-of-life care for the critically ill: A national intensive care unit survey. Crit Care Med 2006; 34(10):2547-2553.

53. Nelson JE, Mathews KS, Weissman DE et al. Integration of palliative care in the context of rapid response: a report from the Improving Palliative Care in the ICU advisory board. Chest 2015; 147(2):560-569.

54. Gisondi MA. A case for education in palliative and end-of-life care in emergency medicine. Acad Emerg Med 2009; 16(2):181-183.

55. Johnson MJ. Breaking the deadlock. British Journal of Cardiology 2015; 22:10-11.

56. Fallowfield L, Lipkin $M$, Hall A. Teaching senior oncologists communication skills: results from phase I of a comprehensive longitudinal program in the United Kingdom. J Clin Oncol 1998; 16(5):1961-1968.

57. Fallowfield L, Jenkins V, Farewell V, Saul J, Duffy A, Eves R. Efficacy of a Cancer Research UK communication skills training model for oncologists: a randomised controlled trial. Lancet 2002; 359(9307):650-656.

58. Meier DE, Beresford L. Fast response is key to partnering with the emergency department. J Palliat Med 2007; 10(3):641-645.

59. Waugh DG. Palliative care project in the emergency department. J Palliat Med 2010; 13(8):936. 
60. Stone SC, Mohanty SA, Gruzden C, Lorenz KA, Asch SM. Emergency department research in palliative care: challenges in recruitment. J Palliat Med 2009; 12(10):867-868.

61. Boland J, Currow DC, Wilcock A et al. A systematic review of strategies used to increase recruitment of people with cancer or organ failure into clinical trials: implications for palliative care research. J Pain Symptom Manage 2015; 49(4):762-772. 
Table 2. Included studies

\begin{tabular}{|c|c|c|c|c|c|}
\hline $\begin{array}{l}\text { Article } \\
\text { reference. }\end{array}$ & Setting & $\begin{array}{l}\text { Study population** (number } \\
\text { recruited) }\end{array}$ & Sampling strategy** & Data collection method** & $\begin{array}{l}\text { Analysis method/ conceptual } \\
\text { framework** }\end{array}$ \\
\hline $\begin{array}{l}13 \text { Bailey } \\
2011 \text { (a) }\end{array}$ & $\begin{array}{l}\text { UK Emergency } \\
\text { Department (ED) }\end{array}$ & $\begin{array}{l}\text { ED staff (15) } \\
\text { Patients (7) } \\
\text { Relatives (7) }\end{array}$ & Purposive & $\begin{array}{l}\text { Participant observation } \\
\text { Semi-structured interviews }\end{array}$ & $\begin{array}{l}\text { Thematic analysis of transcripts } \\
\text { and field notes }\end{array}$ \\
\hline $\begin{array}{l}14 \text { Bailey } \\
2011 \text { (b) }\end{array}$ & UK ED & $\begin{array}{l}\text { ED staff (10) } \\
\text { Patients (6) } \\
\text { Relatives (7) }\end{array}$ & Purposive & $\begin{array}{l}\text { Participant observation } \\
\text { Semi-structured interviews }\end{array}$ & $\begin{array}{l}\text { Thematic analysis of transcripts } \\
\text { and field notes }\end{array}$ \\
\hline $\begin{array}{l}28 \text { Bailey } \\
2011 \text { (c) }\end{array}$ & UK ED & $\begin{array}{l}\text { ED staff (15) } \\
\text { Patients (7) }\end{array}$ & Purposive & $\begin{array}{l}\text { Participant observation } \\
\text { Semi-structured interviews }\end{array}$ & $\begin{array}{l}\text { Thematic analysis of transcripts } \\
\text { and field notes }\end{array}$ \\
\hline $\begin{array}{l}33 \text { Browne } \\
2014\end{array}$ & $\begin{array}{l}\text { A single Scottish Health } \\
\text { Board }\end{array}$ & $\begin{array}{l}\text { a. Patients with advanced heart } \\
\text { failure, symptoms and recurrent } \\
\text { admissions. (30) } \\
\text { b. Their carers. (20) } \\
\text { c. Clinicians (65) }\end{array}$ & Purposive & $\begin{array}{l}\text { a. Semi-structured } \\
\text { interviews. } \\
\text { b. Semi-structured } \\
\text { interviews. } \\
\text { c. Focus groups }\end{array}$ & $\begin{array}{l}\text { Content/framework analysis of } \\
\text { transcripts, informed by } \\
\text { Normalisation Process Theory } \\
\text { (NPT) }\end{array}$ \\
\hline $\begin{array}{l}29 \text { Chan } \\
2011\end{array}$ & A US hospital's ED & $\begin{array}{l}\text { a. Dying patients. (10) } \\
\text { b. Clinicians (8) } \\
\text { c. Clinicians (11) }\end{array}$ & Convenience & $\begin{array}{l}\text { a. Participant observation } \\
\text { b. Short interviews } \\
\text { c. In-depth interviews }\end{array}$ & $\begin{array}{l}\text { Interpretative phenomenological } \\
\text { analysis (IPA) }\end{array}$ \\
\hline $\begin{array}{l}15 \text { Decker } \\
2015\end{array}$ & $\begin{array}{l}\text { Three EDs in a single } \\
\text { Australian tertiary hospital } \\
\text { network. }\end{array}$ & ED nurses $(25)$ & $\begin{array}{l}\text { Convenience } \\
\text { (recruited via open } \\
\text { invitation in department) }\end{array}$ & Focus groups & Grounded Theory \\
\hline 30 & US tertiary centre & Attending physicians (20) & Purposive & Telephone conference focus & Grounded Theory \\
\hline
\end{tabular}




39




\begin{tabular}{|c|c|c|c|c|c|}
\hline 2015 & & & & & \\
\hline $\begin{array}{l}31 \text { Stone } \\
2011\end{array}$ & US ED & Doctors working in ED. (24) & $\begin{array}{l}\text { Convenience (respondents } \\
\text { to invitation) }\end{array}$ & Semi-structured interviews & Constant comparative \\
\hline $\begin{array}{l}34 \text { Tarzian } \\
2000\end{array}$ & $\begin{array}{l}\text { Northeastern United } \\
\text { States }\end{array}$ & $\begin{array}{l}\text { Nurses having cared for people with } \\
\text { air hunger. (10) } \\
\text { Relatives of people who died with air } \\
\text { hunger. (2) }\end{array}$ & Not specified & $\begin{array}{l}\text { Semi-structured interviews. } \\
\text { (all) }\end{array}$ & IPA \\
\hline $\begin{array}{l}38 \text { Weinick } \\
2008\end{array}$ & US hospital & $\begin{array}{l}\text { a. Records of patients over } 65 \\
\text { admitted to hospital from } \mathrm{NH} \text { via ED. } \\
(40) \\
\text { b. ED clinicians. (10) }\end{array}$ & $\begin{array}{l}\text { a. Random } \\
\text { b. Convenience }\end{array}$ & $\begin{array}{l}\text { a. Review of casenotes for } \\
\text { pre-specified information and } \\
\text { location of information } \\
\text { b. Semi-structured telephone } \\
\text { interviews }\end{array}$ & $\begin{array}{l}\text { a. Descriptive statistics } \\
\text { b. Content analysis }\end{array}$ \\
\hline $\begin{array}{l}\text { Summary } \\
19 \text { papers } \\
\text { from } 16 \\
\text { studies } \\
1998-2015\end{array}$ & $\begin{array}{l}\text { Australia (5) } \\
\text { United Kingdom (5) } \\
\text { United States (9) }\end{array}$ & $\begin{array}{l}\text { Clinicians } 482^{* * *} \\
\text { Patients } 61 \\
\text { Carers } 36\end{array}$ & $\begin{array}{l}\text { Methods include random, } \\
\text { convenience, purposive and } \\
\text { one not specified. }\end{array}$ & $\begin{array}{l}\text { Methods include focus } \\
\text { groups), semi-structured } \\
\text { interviews, written surveys, } \\
\text { participant observation, } \\
\text { casenote review. }\end{array}$ & $\begin{array}{l}\text { Analysis techniques included } \\
\text { Content Analysis, IPA, Grounded } \\
\text { Theory, Constant Comparative, } \\
\text { Content Analysis, Thematic } \\
\text { Analysis and descriptive statistics. }\end{array}$ \\
\hline
\end{tabular}

\section{ED: Emergency Department}

*Papers grouped and shaded in grey use the same or overlapping data sets.

**Where separate subgroups are subjected to distinct modes of sampling, data collection and data analysis, letters are used to denote the subgroups. Where not otherwise specified, the same modes apply across the entire study group.

***Qualitative studies/arms only. Totals recruited to quantitative studies/arms (Marck 2014 and arm 1 of Weinick 2008): Clinicians: 681. Patients: 40. Numbers observed in observational studies not known (Chan 2011, Bailey 2011). 
eTable 1. Search Strategy

Search terms (MEDLINE example. Search strategies in other databases were based on similar terms but with Medical Subject Heading terms adapted to be appropriate for the respective databases.)

$\underline{\text { Design }}$

To identify qualitative research papers Flemming's 3 line qualitative filter was used:

1 interview*

2 qualitative

3 finding*

Population

4 Palliative care MeSH palliative care

5 Terminal-care MeSH terminal care

6 Terminally-ill MeSH terminally ill

7 Bereav* MeSH bereavement

8 Hospice* MeSH hospices

9 Palliat*

10 Terminal* adj6 care*

11 terminal* adj6 caring

12 terminal* adj ill*

13 living adj will*

14 advance * adj directiv*

15 advance* adj care adj plan

16 "end of life" adj6 care

17 "end of life" adj6 caring

\section{Exposure}

13 "emergency department*"

14 "emergency medicine" MeSH emergency medicine

15 "emergency room"

16 "emergency treatment" MeSH emergency treatment

17 accident adj3 emergency

18 "emergency physician" MeSH emergency medical services

19 "casualty"

\section{Outcome}

20 reason* adj3 present

21 experience*

22 interact*

23 expect*

24 revolv* adj door

25 prefer* adj3 place adj3 death

261 OR 2 OR 3 
274 OR 5 OR 6 OR 7 OR 8

289 OR 10 OR 11 OR 12

2927 AND 28

3013 OR 14 OR 15 OR 16 OR 17 OR 18 OR 19

3120 OR 21 OR 22 OR 23 OR 24 OR 25

3226 AND 29 AND 30 AND 31 
eTable 2. QARI Appraisal

\begin{tabular}{|c|c|c|c|c|c|c|c|c|c|}
\hline $\begin{array}{l}\text { Article } \\
\text { reference }\end{array}$ & $\begin{array}{l}\text { Is there } \\
\text { congruity } \\
\text { between the } \\
\text { stated } \\
\text { philosophical } \\
\text { perspective } \\
\text { and the } \\
\text { research } \\
\text { methodology? }\end{array}$ & $\begin{array}{l}\text { Is there } \\
\text { congruity } \\
\text { between the } \\
\text { research } \\
\text { methodology } \\
\text { and the } \\
\text { research } \\
\text { question or } \\
\text { objectives? }\end{array}$ & $\begin{array}{l}\text { Is there } \\
\text { congruity } \\
\text { between the } \\
\text { research } \\
\text { methodology } \\
\text { and the } \\
\text { methods } \\
\text { used to } \\
\text { collect data? }\end{array}$ & $\begin{array}{l}\text { Is there } \\
\text { congruity } \\
\text { between the } \\
\text { research } \\
\text { methodology } \\
\text { and the } \\
\text { interpretation } \\
\text { of results? }\end{array}$ & $\begin{array}{l}\text { Is there a } \\
\text { statement } \\
\text { locating the } \\
\text { researcher } \\
\text { culturally or } \\
\text { theoretically? }\end{array}$ & $\begin{array}{l}\text { Is the } \\
\text { influence } \\
\text { of the } \\
\text { researcher } \\
\text { on the } \\
\text { research, } \\
\text { and vice- } \\
\text { versa, } \\
\text { addressed? }\end{array}$ & $\begin{array}{l}\text { Are } \\
\text { participants, } \\
\text { and their } \\
\text { voices, } \\
\text { adequately } \\
\text { represented? }\end{array}$ & $\begin{array}{l}\text { Is the } \\
\text { research } \\
\text { ethical } \\
\text { according } \\
\text { to current } \\
\text { criteria or, } \\
\text { for recent } \\
\text { studies, } \\
\text { and is there } \\
\text { evidence of } \\
\text { ethical } \\
\text { approval by } \\
\text { an } \\
\text { appropriate } \\
\text { body? }\end{array}$ & $\begin{array}{l}\text { Do the } \\
\text { conclusions } \\
\text { drawn in the } \\
\text { research } \\
\text { report flow } \\
\text { from the } \\
\text { analysis, or } \\
\text { interpretation } \\
\text { of the data? }\end{array}$ \\
\hline $\begin{array}{l}13 \text { Bailey } \\
2011 \text { (a) }\end{array}$ & Yes & Yes & Yes & Yes & Yes & Yes & Yes & Yes & Yes \\
\hline $\begin{array}{l}14 \text { Bailey } \\
2011 \text { (b) }\end{array}$ & Yes & Yes & Yes & Yes & Yes & Yes & Yes & Yes & Yes \\
\hline $\begin{array}{l}28 \text { Bailey } \\
2011 \text { (c) }\end{array}$ & Yes & Yes & Yes & Yes & Yes & Yes & Yes & Yes & Yes \\
\hline $\begin{array}{l}33 \text { Browne } \\
2014\end{array}$ & Yes & Yes & Yes & Yes & Yes & Yes & Yes & Yes & Yes \\
\hline $\begin{array}{l}29 \text { Chan } \\
2011\end{array}$ & Yes & Yes & Yes & Yes & Yes & Yes & Yes & Yes & Yes \\
\hline $\begin{array}{l}15 \text { Decker } \\
2015 \\
\end{array}$ & Yes & Yes & Yes & Yes & Yes & Yes & Yes & Yes & Yes \\
\hline $\begin{array}{l}30 \\
\text { Grudzen } \\
2012 \\
\end{array}$ & Yes & Yes & Yes & Yes & Yes & Yes & Yes & Yes & Yes \\
\hline $\begin{array}{l}39 \\
\text { Henderson } \\
2013\end{array}$ & Yes & Yes & Yes & Yes & Yes & Yes & Yes & Unclear & Yes \\
\hline $\begin{array}{l}24 \text { Jelinek } \\
2013\end{array}$ & Yes & Yes & Yes & Yes & Yes & Yes & Yes & Yes & Yes \\
\hline
\end{tabular}




\begin{tabular}{|c|c|c|c|c|c|c|c|c|c|}
\hline $\begin{array}{l}27 \text { Lane } \\
2014\end{array}$ & Yes & Yes & Yes & Yes & Yes & Yes & Yes & Yes & Yes \\
\hline $\begin{array}{l}25 \text { Marck } \\
2014\end{array}$ & Yes & Yes & Yes & Yes & Yes & Yes & Yes & Yes & Yes \\
\hline $\begin{array}{l}36 \text { Payne } \\
1998\end{array}$ & Yes & Yes & Yes & Yes & Yes & Yes & Yes & Yes & Yes \\
\hline $\begin{array}{l}35 \text { Shearer } \\
2014\end{array}$ & Yes & Yes & Yes & Yes & Yes & Yes & $\begin{array}{l}\text { No (Mainly } \\
\text { quantitative } \\
\text { results reported } \\
\text { on) }\end{array}$ & Yes & Yes \\
\hline $\begin{array}{l}22 \text { Smith } \\
2009\end{array}$ & Yes & Yes & Yes & Yes & Yes & Yes & Yes & Yes & Yes \\
\hline $\begin{array}{l}23 \text { Smith } \\
2010\end{array}$ & Yes & Yes & Yes & Yes & Yes & Yes & Yes & Yes & Yes \\
\hline $\begin{array}{l}37 \\
\text { Stephens } \\
2015\end{array}$ & Yes & Yes & Yes & Yes & Yes & Yes & Yes & Yes & Yes \\
\hline $\begin{array}{l}\text { 31 Stone } \\
2011\end{array}$ & Yes & Yes & Yes & Yes & Yes & Yes & Yes & Yes & Yes \\
\hline $\begin{array}{l}34 \text { Tarzian } \\
2000\end{array}$ & Yes & Yes & Yes & Yes & Yes & Yes & Yes & Yes & Yes \\
\hline $\begin{array}{l}38 \\
\text { Weinick } \\
2008\end{array}$ & Yes & $\begin{array}{l}\text { Yes (Multiple } \\
\text { research } \\
\text { questions } \\
\text { requiring a } \\
\text { variety of } \\
\text { methodologies) }\end{array}$ & Yes & Yes & Yes & Unclear & Yes & Yes & Yes \\
\hline
\end{tabular}


eTable 3. Themes identified in synthesis of 19 studies: Environment and purpose 
blamed it on the busyness of the emergency staff." (12)

"Providers and patients alike described the ED as a tremendously busy place with competing demands for providers' attention. In a busy ED, there is an inherent tension between maximum efficiency of the medical workup of a patient and the ability to move a patient to the inpatient setting." (20)

\begin{tabular}{|l|l}
\hline Low prioritisation & $\begin{array}{l}\text { "Joe described how he felt he had been left in a corner, once his initial breathing was stabilised. Like many of } \\
\text { the other patients observed in the study, he described how no one came to check on him before he was } \\
\text { transferred to the ward." (12) }\end{array}$
\end{tabular}

"During the observations, the movement and location of patients had a considerable impact on the attention they received from the emergency staff. Patients were triaged and placed in particular area of the ED depending on their presenting compliant. The space in which they were assigned reflected the attention the staff felt they required. This highlighted that staff continued to prioritise life saving treatments and consequently neglect the needs of patients who were in need of supportive and palliative care" (12)

"We didn't feel supported really but they are just nurses doing their job and they have got a lot to deal with really. I mean the cubicles were full. No, he wasn't a priority at all (Rose, wife of patient admitted)." (12)

"Staff nurse Anthony said that "your attention has to go to the resuscitation so the patient that is dying will be left and will be checked on intermittently and that's not how it should be, that's not how you want it to be." (25)

"Not to say that they don't deserve the attention and everything, I just think it is the environment. There is so much going on and I think unfortunately patients with palliative care needs do get put on the back burner sometimes." (19)

"Another physician expressed the view that palliative care needs are lower priority when compared with other actions they must perform in a busy ED: "It isn't the logistical lack of availability. From my perspective, this isn't the top of the list of things that I must accomplish." (27)

"Participants reported that due to the nature of the ED, caring for palliative and dying patients was a low priority. Blaming time constraints and a lack of resources, the participants described how the nursing care of more acute patents who were perceived to be likely to survive, or have an improved patient outcome were considered a higher priority: And we can't prioritise him [the patient at EOL] because we've got all these other ... [resuscitation] patients coming in who need immediate attention" (13)

"No nursing care intervention would change a dying patient's prognosis, which is why the nurse perceived the dying patient's care to be a low priority:. . . if you've got somebody who has died, and there is nothing that you can do, sometimes they do come last because ... [there is a] patient next door who you can help right now." (13)

"I've seen it so many times and if the patient's going to die, and hopefully we can get them upstairs to the side room to die, if not we'll stick them in bay 10 [corner bay] out of the way pull the curtains pop your head round every few minutes or if we get busy every half hour and it's like ... oh well. It [segregation] does happen and I don't like that." (12)

"The use of the relatives' room highlighted the emergency staff's attempt to separate relatives who are bereaved and relatives anticipating bereavement from their loved ones. Relatives of patients who had a high potential for death were separated from the main clinical area and placed in a room away from their loved one and other people in the ED. The use of the relatives' room in the ED was symbolic to the severity of the patient's condition. The isolation of relatives into a separate room allowed staff to communicate to other staff, the high potential for the death of the patient." (12)

"While accessing emergency services for symptom control or supportive care as death nears, the triage of these patients to less visible areas in the ED tends to result in less attentive care. While some end-of-life trajectories are judged as appropriate for the emergency setting, it is evident that others are clearly seen as 'out of place' and consequently the dirty work of dying can be concealed. This can potentially be damaging to dying patients and their relatives." (12)

"The actions of participants to move dying patients out of the ED also indicated the lack of acceptance of the ED as a place for death. The emergency nurses in this study described experiences of caring for a dying patient that involved pressure and a sense of urgency to 'move them out'. The participants also described how once a 
Relatives proximity to the patient patient was believed to be dying that they were promptly moved 'out the back' or to 'the cubicles' because they no longer required life-saving treatment." (13)

"Dying patients and their bereaved families were either cared for away from the rest of the ED in corner rooms, and 'the relative's room', or promptly transferred out of the ED." (13)

"Mara had been moved to the corner bay with the curtains drawn, concealing the space in which she was dying. From the point that her active treatment was stopped and the do-not-resuscitate order written (a period of 3 hours 20 minutes), Mara was checked on only once by a staff nurse during shift handover. During this observation, the rest of the ED was at its usual busy state, but most of the staff attention was focused on Brian in the trauma bay. Brian received constant nursing presence and comfort care, but Mara did not." (25)

"Joe, a 67-year-old man with terminal lung cancer, fitted our observations that patients in the subtacular trajectory are, although often segregated to less visible areas in the ED for privacy, effectively hidden away. He described being "stuck in a corner and left there." (25)

"The lack of 'calm' conferred by the high level of activity was compounded by a lack of space for families who required complex and sensitive information provision or who simply wished to be present if their relative or friend was actively dying." (21)

"The use of the relatives' room highlighted the emergency staff's attempt to separate relatives who are bereaved and relatives anticipating bereavement from their loved ones. Relatives of patients who had a high potential for death were separated from the main clinical area and placed in a room away from their loved one and other people in the ED. The use of the relatives' room in the ED was symbolic to the severity of the patient's condition. The isolation of relatives into a separate room allowed staff to communicate to other staff, the high potential for the death of the patient." (12)

"If someone is dying and we can't get them upstairs we really do try and put them [in the single room] where their family can sit with them." (24) or years after a diagnosis before someone decides to change their care goals away from aggressive treatment; however, I feel it is our responsibility to assist patients who are further along in this decision process." (19)

“(A) large proportion... agreed that the ED is 'not the right place to die' with a small number (16\%) agreeing to the strongly worded statement 'I would avoid my patient dying in ED no matter what" (22)

"It is the scenario I try to avoid at all costs. I would not like a family member or friend to die within ED and my patient care is delivered as I would care for my own family." (22)

"Although a large majority of ED clinicians consider caring for the dying a reasonable demand on them, they overwhelmingly believe that the ED is not the right place to die." (22)

"All clinicians described the ED as a less than ideal environment for patients with advanced cancer." (21)

"Clinicians from other disciplines reiterated that dying in the ED was to be avoided. As stated by a PC nurse: It probably leaves us with negative feelings, like if you're at client review and you say someone was transferred to hospital and died in an ED everyone collectively goes 'oohhh'. Not a good outcome." (21)

"All the pressure means that the quality of care isn't good. Patients don't want to die on a trolley in a busy ED. It's not the ideal place. There isn't an ideal place really but a side room would certainly be better so there is pressure to get patients up there [to the ward] but it's as if the care doesn't matter. It's the time that matters the time they're in the department is all that matters rather than the quality of care." (12)

"The ED setting is generally not seen as the appropriate place in which dying should occur; such an occurrence can be perceived as unnatural and out of place and potentially tainting a setting that is positively associated with saving life." (12)

"The often busy, loud, and overcrowded ED is not the optimal treatment location for many patients with terminal illness, and these findings suggest a gap in our system's ability to care adequately for these patients at home" (20)

“'Dying in the ED is not ideal'... The participants identified that it was not ideal for death to occur in the ED and 
that this was central to their experiences of death and dying in the ED. All participants commented on the negative impact that the ED environment had on their ability to provide care that ensured that a dying patient experienced a good death." (13)

“The participants' believed that a dying patient and their family were unlikely to experience a good death in the ED because the environment could not support the necessary elements to ensure quality EOL care." (13)

Purpose of the ED

\begin{tabular}{|l|ll}
\hline Role of palliative care & "The ED can be an appropriate place for patients with advanced cancer and sudden, unpredictable change in
\end{tabular} their condition, or as a safety net for a 'dying at home' plan, where patients or their family need unexpected additional support." (22)

"ED clinicians clearly consider ED presentation legitimate in the care of advanced cancer patients and perceived particular benefits to patient care, such as providing the objective view of an ED physician to aid goal-setting or other decision-making. When caring for dying patients, emergency clinicians did their best to ensure the best possible care and environment was provided, and found this a rewarding and worthwhile part of their work." (21)

"Some providers believed that palliative care has a "negative" connotation among ED providers, whose goals primarily focus on stabilization, diagnosis, and disposition. Others, primarily nurses, disagreed, and thought that palliative care was consistent with the goals of emergency medicine and that caring for these patients was an intensely rewarding experience." (19)

"This is an overgeneralization, but I think that palliative care has a little bit of a negative connotation in the ED. If you think about people who go into emergency medicine, they want to sort of act and do, cure. When someone comes in and their status is DNR or comfort care, it is not necessarily seen as a priority or as a good thing. The first reaction is almost "Why are they here? Why are they bothering us? This is not an emergency." (19)

"The over-arching theme to emerge was that emergency clinicians found themselves 'caught in the middle' while caring for people with advanced cancer; not only did the emergency clinicians find that their practice was fraught with difficulty, related to the environmental inadequacies of the ED and resource limitations, but the care of people with advanced cancer was also challenged by tensions in expectations and views of the role of ED staff, such as the tension between the perceived ED role of 'saving lives' and a palliative approach to care." (21)

"Many physicians also expressed uncertainty regarding how to integrate palliative care into their practice of emergency medicine... Another physician from a community hospital explained that he was "not always clear what the expectation is or what my role is" when hospice patients come to the ED." (27)

"The ED is often the place where end-of-life decisions are made. Some emergency patients are in need of symptom control and supportive care not resuscitative intervention, yet their need for rapid, attentive, patient-centred, quality care is equally important." (12)

"Several described palliative care as being somewhat at odds with standard medical training where individuals are trained to cure patients and want to "fix" things." (28)

"The ED focus is on saving life, and reluctance exists among emergency staff to concede that nonemergency death and dying constitute a large part of emergency work. This, along with the distancing behaviors, which some staff exhibited to avoid getting involved with the dying and bereaved, means that palliative and supportive care needs are often not provided in the ED." (25)

"Many ED staff regarded palliative care as holistic and therefore as more than just alleviating physical symptoms. In the words of one respondent: 'palliative care is the care of a dying patient including physical, emotional, social and spiritual'." (32)

"Participants equated palliative care with an effort to reduce symptoms in patients who were actively dying, a concept often referred to by participants as "comfort care." (19)

"Resident physicians in particular discussed the inadequacies of current training in pain management. One resident said that he had "rarely" been taught how to manage pain: "One attending talked to me for 10 minutes about good ways to manage pain, how to approach it more systematically, and I really appreciated it 
Healthcare professionals' comfort in providing care and it is very rare to get that sort of teaching about how to manage pain." Another physician stated, "I think that if I really felt $100 \%$ comfortable that all of the patients that I have taken care of while they were dying were completely comfortable, I would feel better about it, but I have had a lot of patients that I have taken care of that I wonder. . .did I really do everything, or did we just kind of let this person die?" (19)

"Although acutely worsened pain or dyspnea was often cited as the instigating reason for admission to the ED, providers thought that family members, rather than patients, were uncomfortable managing these symptoms at home." (19)

"April, an emergency department (ED) nurse, described how one patient "was so anxious for air, [he had] just that kind of wide-eyed panicked look that people get when they can't breathe." "The patient's look" refers both to how air-hungry patients were described by nurses, as well as how patients actively looked toward the nurse, beckoning her for help." (31)

"April remembered one ED physician who, when asked for a narcotic order to make a terminally ill patient more comfortable, told her, "Well, he'll be unconscious soon." The nursing home patient Teddy described above was finally made comfortable, to the relief of the patient and family. Yet her respiratory difficulty returned when staff nurses withheld doses of lorazepam and morphine for fear they were overdosing her." (31)

"Palliative pain control is a very specialised area. I think most EDs are quite blunt with how they manage pain, and certainly the options that are considered by palliative care specialist may not even be known about by a lot of ED doctors.'” (21)

"I was treating a patient for pain and when the house staff came to see him, they also felt very uncomfortable with his care because they're used to treating a patient for a disease and not for pain. They're not used to dealing with these patients, so I think that palliative care consultation services would be very helpful in educating the staff." (27)

"At the index visit, all participants were seen in the ED for symptoms that patients and family caregivers felt unable or unprepared to manage at home. In nearly all cases, patients or their caregivers contacted the outpatient provider and were advised to go to the ED. The following quote from the wife of a 56-year-old man with metastatic cancer, who developed back pain (eventually diagnosed as spinal cord compression), is representative: I was trying to get him to sleep one night and he was in a lot of pain. I was giving him more Dilaudid on top of more Dilaudid, and I gave him so much medication and it wasn't even touching [the pain]. I thought I was going to overdose him because he had so much." (20)

"Although pain was the primary complaint for half of the patients, several patients experienced pain in addition to another symptom that brought them to the ED. The theme "pain management is essential" was pervasive, where 14 of 21 patients described incomplete pain management. "Effective treatment of pain" was noted in six interviews." (20)

"Inadequately treated pain was a major reason for dissatisfaction with the ED encounter. Patients came to the ED with symptoms, yet in some instances, either waited in the waiting room in discomfort or were treated ineffectively in the ED." (20)

"Patients in this trajectory were most frequently brought into the ED by ambulance from their homes or care homes. Presentation complaints on arrival to the ED included collapse, dyspnea, gastrointestinal bleeding, fall with associated injury, or acute symptoms associated with terminal conditions such as pain" (25)

"Our clinical ED staff also expressed greater confidence in dealing with many of the clinical aspects of palliative care, including pain management, which was not consistent with the findings of many other studies. Comfort in this area might be expected of ED staff as acute analgesia is a core ED skill." (32)

"However, this (development of patient-practitioner relationship) is frequently not carried out because some staff distance themselves from the patients and their relatives, apparently in an attempt to protect themselves from the potential loss or upset they may experience when death occurs." (25)

"One nurse described caring for dying patients as a privilege: "When you can pull back all of the wires and everything and be in that room and comfort that family and make that patient comfortable, and give the perfect environment for what they need-to me is a privilege. To be present when the patient dies is a very sacred experience." (19) 
Building relationships with patients
"I think that we are very comfortable with diagnosis and treatments and doing things for people. Seeing the bigger picture and just witnessing end of life is something that is a little bit harder for us to deal with emotionally." (19)

"The vast majority of respondents agreed that 'caring for a dying patient in the ED is a reasonable demand on them' and that they 'felt comfortable managing a dying patient', with $70 \%$ agreeing that 'it is rewarding caring for a dying patient'." (22)

"Helping someone die in comfort and dignity ... is some of the most rewarding clinical experiences I have. I feel I have not been able to completely provide the care, respect and dignity for the patient who dies within the ED." (22)

“Most ED nurses come from a high-tech background where you're used to jumping in and doing very important, very high-tech things to help save people's lives. And to just essentially stand there and watch people die, struggling for air, is very anxiety producing. Responding to this crisis required a new vision of "doing everything" for a dying patient-a kind of "intensive caring" that did not include extensive invasive technology. Such perceptions of maintaining or losing control were influenced by the location where care was provided." (31)

"Despite the limitations of the environment and training, ED clinicians universally reported a profound respect for the opportunity to provide care to patients with advanced cancer and a sense of personal enrichment when doing so" (21)

"I think it's . . . personally ... a very humbling experience ... especially if you might've only met them for 5 minutes or it could be 8 hours or 10 hours of your shift and you're still travelling that journey with them. And . .. what you do and what you say and how you interact with them matters. Every minute of it matters." (21)

"I love it [caring for patients with advanced cancer], personally. I think being able to intervene quickly and in a gentle efficient way so that someone doesn't have to deal with the sort of systemic rubbish, of lying around and waiting, being uncomfortable and being frightened, I mean it's a great opportunity to doctor in the purest sense." (21)

"When faced with the widely acknowledged challenge of caring for a person with cancer actively dying in ED, they described 'going the extra mile' to provide optimal care in a difficult and imperfect environment, and the personal and professional satisfaction this could provide" (21)

"Attending physicians reported the most rewarding aspects of their job were "being able to connect with the patients and families," "to assuage fears," or "to educate or explain something." One physician expressed particular satisfaction with "being able to transition a family from an aggressive course of care to a mode of comfort care." (27)

"'Thinking that I had a chance to guide a family through a very delicate decision and help a patient realize exactly what he wanted to do that makes me feel very satisfied as a health care provider." (28)

"ED clinicians in this study felt comfortable caring for dying patients and reported finding this rewarding" (24)

"ED staff felt confident delivering clinical aspects of palliative care, they lacked understanding of the scope and goals of palliative care, and potentially the communication skills to handle endof- life discussions." (32)

"When it did fall to ED providers to have goals of care discussions with patients and families, providers found these conversations challenging, primarily because they had no established relationship with these patients, who were often acutely decompensating. Another physician summed it up this way: "It is shocking how often I am the first person to document DNR status in the chart ... on an ER visit."' (19)

"It's a very difficult situation for us because we're only caring for the patient for a very short period and then we usually give the patient's care to someone else. It could be a specialist whose plan of care we don't agree with, which is difficult for us." (27)

"The nurse is ideally placed to challenge existing practices and help improve the quality of end-of-life care during the emergency admission through the developing the nurse-patient relationship, maintaining communication and acting as an advocate for patients during their crisis. Our data can therefore inform relevant professional development activities, and contribute to the broad field of nurse and ED staff 


\begin{tabular}{|c|c|}
\hline & $\begin{array}{l}\text { education." (12) } \\
\text { "Irrespective of their condition, prognosis or extent of symptoms, the patients evaluated their experience of } \\
\text { care in the ED largely on the basis of the level of attention they received and the relationship they had with } \\
\text { those providing their care." (11) } \\
\text { "The findings reveal that the investment of the therapeutic self into this relationship can have a positive } \\
\text { impact on the patient experience. During the interviews, the nurses expressed the value of the 'therapeutic } \\
\text { self' as intrinsic to 'knowing the patient' and recognising their individual needs." (11) } \\
\text { "Neither Joe nor his wife Rose could identify one particular nurse who had cared for him during his ED stay and } \\
\text { he described feeling 'stuck in a corner and left'. Patients seem to view nursing care not necessarily by what is } \\
\text { done but more to do with how it is done." (11) } \\
\text { "Care in these exemplars reveal that emergency clinicians were engaged in the care of patients as they } \\
\text { approached death or were dying. These clinicians did not abandon the patient or family during this time of } \\
\text { difficult transition. Recognition of approaching death helps clinicians decide what interventions might be } \\
\text { beneficial to the patients and families." ( } 26) \\
\text { "Unlike the spectacular death, there is the potential for the patient-practitioner relationship to develop in the } \\
\text { subtacular and a space in which end-of-life choices can be discussed and implemented." ( } 25 \text { ) }\end{array}$ \\
\hline Caring for relatives & $\begin{array}{l}\text { "No, most people who are dying are relatively easy, they are ready to die and have accepted it, it is the } \\
\text { relatives that are more difficult." (33) } \\
\text { "The care of relatives was also resigned to EDAs. Although they often did not feel prepared for this role, they } \\
\text { acknowledged that the personal care of the dying and care of the relatives was a big part of their work... } \\
\text { usually show the relatives to the room which can be difficult because I think they must think the worst. } \\
\text { Sometimes it's a case of blagging it a bit to be honest with you just saying you know there's nothing I can tell } \\
\text { you at the moment, but we are doing everything we can, we will keep you posted, keep you informed. Half the } \\
\text { time, you are just filling in the gap" (12) } \\
\text { "There is something different between [death from] an accident and people who die slowly in the department. } \\
\text { It still can be as difficult to deal with. I think the real pressure comes from being with the relatives or dealing } \\
\text { with someone who is dying slowly [as] you're there with them." (25) }\end{array}$ \\
\hline
\end{tabular}


eTable 5. Themes identified in synthesis of 19 studies: System of care and interdisciplinary working

\begin{tabular}{|c|c|}
\hline Communication & \\
\hline Breaking bad news & $\begin{array}{l}\text { "Some of the most obvious challenges are language barriers that may exist between patients/family and the } \\
\text { ED physician. The sensitive nature of end-of-life conversations is difficult enough in English and compounded } \\
\text { when attempted in a foreign language.... In addition to linguistic barriers, respondents also reported additional } \\
\text { cultural barriers including differing religious and spiritual beliefs and limited health literacy." (28) } \\
\text { "Distress was also experienced when advocating for dying patients and their families when they remained in } \\
\text { the ED. One participant described a scenario in which she had to explain to the relatives that were with them } \\
\text { [the dying patient] that it [was] possible for them [the dying patient]to die en route [to the ward], which [was] } \\
\text { a very awkward conversation to have. The participant reported being distressed over the risk of death en } \\
\text { route to the ward, simply to make another bed available to the next ED patient." (13) } \\
\text { "We found a great lack of communication to be quite honest because they [the ED staff] were very busy ... so } \\
\text { the information wasn't very forthcoming. It wasn't until Dad got here [the Specialist Palliative Care Unit] that } \\
\text { answers started to become apparent. I think from our point of view, purely from the frustration as a family } \\
\text { member, I wanted to know what was going off. The lack of information was infuriating." (25) } \\
\text { "Perhaps most important, according to our physician respondents, is that the counselling and consult of the } \\
\text { palliative care team can help family members "face the reality of where they are" and help them come to } \\
\text { terms with the terminal nature of their loved ones' diagnosis. One physician explained: "Letting people realize } \\
\text { it's okay that their family members are very ill or dying and they just won't get better." (28) }\end{array}$ \\
\hline $\begin{array}{l}\text { Quality of } \\
\text { communication }\end{array}$ & 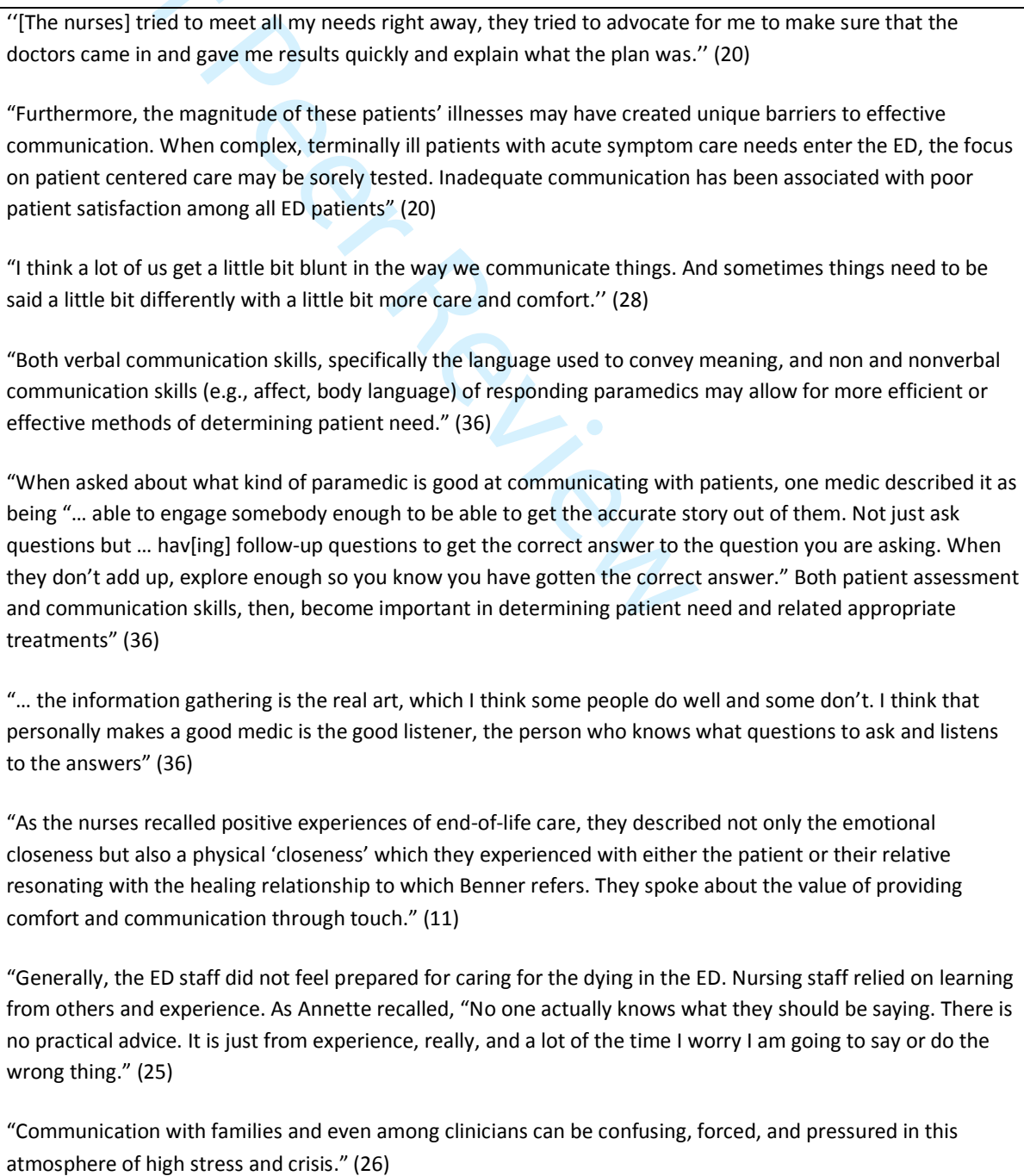 \\
\hline
\end{tabular}


"One 52-year-old man with cancer stated: "It is just the uncertainty of when you go to the Emergency Room, you don't know what is happening to you, you don't know what is wrong with you." Or, as another patient explained: The stretchers are not comfortable. They put you in that room, they close the curtains, and they just leave you in there. You don't know what is going on. So they say, "Okay, we are going to admit you, you got a room," but you are still waiting, and you are just wondering, "What is going on, what is taking so long?" (20)

". . .we will tell the doctor, you know, doctor, you've got to explain to the family about her condition that this is, you know, what's the goal." (34)

"I think sometimes they don't talk to patients. I've been there before now and they have just come and stuck a cannula in. My Dad is blind and that is enough for him to hit out at the staff. They need to explain what they are doing not just throw him about you know? They are just so busy (Julie, daughter of patient admitted)." (12)

"All interviewees reported the importance of high-quality communication of information between services, the realities of practice meant that this was often compromised by other service-based imperatives." (24)

"I had 2 or 3 instances that involved a very angry phone call from a primary care physician or an oncologist, who understandably had had a several month conversation with this patient, finally getting him to move to this DNR/DNI comfort measure state, and then they come in and now we have them intubated in the ICU, you know largely through miscommunication. Part of the problem involves being able to communicate effectively with people who know the patients better-their primary care providers, their oncologists - but who aren't there at the ER at the time the patient comes in." (19)

"Providers observed that outpatient providers know patients better than ED providers, and in fact improved communication with outpatient providers was ranked as the highest priority for intervention." (19)

"Improved communication between services is a clearly identified need and likely to be aided by the increasing use of electronic medical records... Improving care for advanced cancer patients will require improved communication between all care providers and an increased recognition of the important role ED clinicians play in their care." (21)

"The patient and caregiver reported that the oncologist contacted the ED to advise them to obtain a magnetic resonance imaging scan to rule out spinal cord compression, but the need for aggressive pain management was not communicated effectively." (20)

"56-year-old man with cancer and spinal cord compression discussed earlier the caregiver described a lack of coordination of care and effective communication between ED and palliative care providers. [The nurses and the palliative care provider] were butting heads. I saw a couple of the nurses and they were just like pissed at her, the nurse said [to us], "You can have [the pain medication] every 2 hours," but [the palliative care provider] had the order written for every $1 / 2$ hour to 1 hour the nurse just didn't want to deal with giving him the pain medications that frequently." (20)

"All interviewees reported the importance of high-quality communication of information between services, the realities of practice meant that this was often compromised by other service-based imperatives... Participants from all services reported that high-quality communication between services and departments was required for optimal care." (24)

"Oncologists reported they did not wish to provide extensive written information about their patients, preferring to be contacted by ED and thereby guide treatment decisions. However, ED doctors reported difficulty contacting the 'right' oncologist after hours. Whilst the ED doctors reported seeking guidance regarding management and goals of care from oncologist's clinic letters in the medical records, the oncologists viewed these clinic letters as a record for their own service and instead preferred to be directly contacted for management decisions to minimise ambiguity or misinterpretation of treatment intent.

I don't think anyone could make a prognostic judgement from reading that letter [oncology clinic letter]." (24)

"Ultimately, ED providers, outpatient care providers, and palliative care providers need to work together to move toward interventions and system changes that improve the quality of care experiences for seriously ill patients and families who are seen at a vulnerable time: acutely symptomatic, anxious, waiting, and wondering what is happening to them, in the busy and crowded confines of the ED." (20) 

to their notes and letters.

...I often find...I get a response from the [ED] triage nurse that is, "well why are you telling me all of this, they're just going to be treated in order anyway so don't, don't bother" (24)

"Although it is feasible to identify AD information in hospital records, many nursing home patients arrive in the ED without an $A D$, and when such documentation is sent, it may not agree with other documentation in the hospital record, limiting its use." (35)

"There is a routine path that patients presenting to ED take, including intravenous cannulation, blood tests and X-rays, which might not be appropriate for a patient with an established terminal illness. This uncertainty about the optimal approach to care was compounded by the lack of, or a delay in, receiving clinical information. The lack of information was a source of considerable frustration and resulted from inadequate clinical notes in the medical record, unavailability of the medical record or of the treating or referring physician, or indeed a combination of these." (21)

"The ultimate question from the perspective of patient-centered care is whether the preferences of patients for end-of-life care are being followed in an emergent setting. As one of our clinician respondents commented when referring to resuscitation, "if someone's already thought about (an AD), we need to have it (in the ED). The question is, how do you make sure the information is communicated before someone has (an endotracheal) tube in place?" (35) have is 'has this (end-of-life care) ever been discussed with you?' And it surprises me, that in more cases than

"The over-arching theme to emerge was one of a conflict between a view of 'ideal care' and the realities of care. Various services working together as a team was also widely considered a requirement for high quality different complications of their illness. Many advanced cancer patients attend the ED during the course of should also be sought when cancer services are planned and developed, and their role considered when sourcing information on which to base important communication with advanced cancer patients about

"Other subjects, however, expressed frustration at being asked the same questions by multiple providers, work in shifts. Some described a feeling of distance and impersonal interactions. For example, one patient who

I have had the pain for over a year, so I have a long history, so something should be written [about me], not "I'm always looking for a letter from the oncologist, the treating oncologist so you know what to do. Sometimes they write it [in] their correspondence;... whatever they have discussed with the patient or what their feelings were regarding the treatment." (24) [the] DNR slip, the original form, whose signatures are on it-does this belong to the patient?" One nurse (he official Massachusetts DNR bracelets are flimsy, susceptible to water damage, and rarely "Without high-quality information about a patient's illness and previously negotiated goals of care, complex decision-making may be impeded in a setting where medical treatment is the usual default." (22) prognosing and had visited the ED on multiple occasions stated: like some person who just comes in and has the flu..." (20) 
not, it hasn't even been broached." (21)

"And the most common thing is ... that it takes the ED presentation to get people thinking about these things [end-of-life care], whereas these things should be addressed well in advance." (21)

“. . we have one long, long, long, long-term son who sends his mother to the emergency room probably once a month at least, and won't let her go. And the emergency room doctors cannot do anything with him; neither can all the other doctors. So they're used to seeing him, they don't do anything more; it's just a trip back and forth. And some of these things could be, I think, [pause] handled better if the physician who is responsiblethe attending physician-had more of a relationship with the family." (34)

"It is shocking how often I am the first person to document DNR status in the chart ... on an ER visit." (19)

"Having these conversations in the ED causes a lot of consternation. I wonder, 'Am I doing the right thing by this person? Why hasn't somebody else talked to this person about it? Why does it come to me to end up talking to this person?" (19)

"Sometimes it's the ED doctor who is the first to seriously (eye to eye ball) express to the patient with advanced cancer what it means to die ... I have had patients discharged from major cancer centres who come to ED distressed and confused and nobody had told them what to expect." (22)

"It would be ideal for patients and their families to have discussions regarding limitations of care, prognosis, and PC (palliative care) with doctors that they know prior to ED. Otherwise, the first time they have this conversation is with ED doctors who they do not know, and this causes unnecessary anxiety." (22)

"The primary care physicians or oncologists often fail their patients and families because they haven't raised the issue and I'm forced to do so in the extreme situation." (27)

"If we're the ones who have to activate a palliative care team, then that's suboptimal. We do it because we're in a situation where it hasn't been done." (27)

“Emergency physicians' felt it was difficult to develop trust with patients because of the short time spent with patients and lack of long-term relationships. For this reason, respondents felt some discussions would best be initiated in the outpatient setting where the physician has more frequent contact with the patient." (28)

"Respondents pointed out that the provision of this kind of care may be more advantageous in a primary care setting given the primary care provider's ability to develop greater trust and rapport with patients and families" (28)

"A lot of the times I've seen patients [that] have a palliative diagnosis [and] nobody's had that discussion ... and that becomes a really difficult situation at times to then bring it up after seeing them for ten minutes." (24)

"You almost do wonder, whether ... each patient, with a potentially incurable disease actually needs an independent doctor, who is not involved with them, to actually discuss end of life issues with them." (24)

"I don't think it's appropriate for them to be having discussions on limitations of care..., I would feel uncomfortable if they're having those kind of discussions to be fair,.... You know if someone's clearly deteriorating in front of your eyes and you need to make a call it's a whole different ball game, then it's fair and I agree that's their role." (24)

"Usually oncology patients have a long road, (they are) very sick. (It) appears that it is a discussion that they should have had, but haven't. We ask the oncologist first, have you discussed end-of-life issues? (When they say no,) we think "why not?," but realize that they have had a long relationship (with the patient) and so defer to the oncologist's judgment. I feel like I could've started the conversation, but it's weird that I see the patient 1 time for 10 minutes and then I'm bringing it up." (35)

"Palliative care should optimally be introduced to patients as a standard component of high-quality multidisciplinary care early in the course of their illness trajectory before a crisis in symptoms that precipitates an ED visit." (20)

"Without previous discussions on the goals of care and advance directives the ED physician has to make the decision whether to prolong life. The palliative care team may not be able to respond rapidly to these cases 
"All physicians felt strongly that "the patient has a right to know." One physician described feeling "torn sometimes because I grew up in that culture; I'm also obligated to make the patient aware of their disease." (27)

"A physician in practice 10 years noted the "conflicting rights of the patient versus the rights of their family members." As a physician, he claims that he is "responsible for the patient and their rights supersede everyone else's." (27)

"The importance of patient informed decision making was described as the highest value. Respondents did not feel that patients were aware of their clinical status. Several respondents mentioned that "I don't feel like many of my end-stage patients understand their prognosis" - often due to lack of primary care, unreasonable expectations, or limited health literacy. In these cases, respondents still felt that patient informed decision making was of high importance and it was the medical team's job to ensure that patients make the best decisions possible." (28)

"Staff held strong views that patients should be actively involved in care decision making" (32)

"The participants perceived that the care provided to a dying patient in the ED was influenced by whether or not the patient's treatment wishes at EOL were known. When a patient was approaching death, the participants described patient scenarios in which they perceived a change in the acceptance of death by emergency staff when they knew a patient's wishes or had a not-for-resuscitation order avail-able. In the absence of knowing what a patient's treatment wishes at EOL were, the participants reported engaging in more active and aggressive life-saving treatment despite a predictable poor patient outcome. From such patient scenarios the participants emphasised the value of not-for-resuscitation orders and documented EOL treatment wishes during the treatment decision-making process:. . . In terms of knowing ... how to treat the patient and ... what the plan is for the patient, I think it's good to know. ... So I think that makes it [death] good." (13)

"Moral distress can occur when conflict exists among ED nurses, physicians, RTs, the patient, or the family." (26)

"The patient came with a comfort measures only/do-not-hospitalize piece of paperwork-very demented patient, couldn't even speak in complete sentences, couldn't process anything that we said, and that was her baseline according to all of the records that we received. The family member reversed everything while I was on the phone, saying 'I do want her hospitalized, and I want you to do everything possible." (19)

"The family members don't give patients enough credit, and if the patient is competent, they have some idea of what's going on, then you have to deal with the family dynamics and the lack of communication." (27)

"It is common for families to react to physicians' decisions: "Here is this new person confronting them with the reality of the situation. They do get mad. They do get irritated." (27) 


\section{Accessing care}

Relatives instigating escalation of care
"Several physicians recognized this, describing the challenge of pleasing both the patient and the family, who sometimes have different needs. Physicians reported that often times, family members expect and request that the medical team do "everything possible" for the patient, often wanting heroic measures from the medical team to keep their family member alive. Physicians reported that in these cases when speaking with family members about end-of-life issues, their main goal is to prepare and educate while providing support." (28)

"Attendings' greatest frustration was when this could not be achieved because of cognitive deficits, family conflict, or when they felt they had to "provide futile care." One described a situation in which "a lot of people are involved and trying to bring them to consensus can be a challenge;" other times, this occurred because of a "patient's or a family member's lack of appreciation that they are at the end of life." (27)

"Bystanders were important in that they had either access to information about the patient or some other knowledge about the patient's condition that was helpful to paramedics to make informed decisions. These individuals were influential in either the information they brought to light or the nature of the means of communicating that information to paramedics." (36)

"Providers described multiple instances in which patients' wishes or written advance directives were in conflict with the wishes of family members. In each case, the patient's documented DNR preference was overturned by family members. Providers in our study were distressed and conflicted about what to do in these cases but defaulted to providing life-prolonging care, partly because of fears of litigation." (19)

"Some perceived they were required to provide futile care because of 'unrealistic expectations' of families, patients and at times the treating inpatient teams." (22)

"However, many physicians in our study would welcome an opportunity to avoid aggressive interventions that they may feel are not in their patients' interests but feel compelled to do because of pressure from family members or medicolegal concerns." (27)

“"I'm not quite sure how that happens [hospital DNR patients reverting to full code on return to NH]. I think part of it is that in the hospital, they'll [patient/family] accept a DNR status, because they feel like they're in an acute [care] setting, but that the family members change their mind, because they're afraid that if they're DNR in a nursing home, that not enough will be done. So they make themselves full code while they're in the nursing home, and then with the understanding they'll probably switch back to DNR when they get to the acute." (34)

"I can think now, probably 5 people with families, that one person has been appointed, the 'primary', or like 'executor person' that will be making the decisions. And then you'll have the other - maybe two other family members coming in at different times during the week, or during the month and it's like 'no one told me about my dad', or 'no one told me this about my mom', and it's just a hard place to be in. .." (34)

"Despite the discharge education from the other hospital regarding prognosis and the role of hospice, the family felt obligated to do something for the patient and activated EMS." (26)

"Families were commonly perceived as the major reason NH residents experienced potentially unnecessary transfers to the hospital... NH health care providers further related that they often made transfer decisions against their best clinical judgment because of this family influence" (34)

"They wanted to take him to the hospital, clearly, but I didn't want that. . family has a lot of influence. The family upset at the bedside and pushing for a transfer to the hospital - not doing that is going to lead to more problems in the long run, and the patient is certainly going to end up in the hospital. One way or another, they're going to end up in the hospital with an angry family member rather than a family member who feels like you've addressed their concerns." [physician]" (34)

"Providers perceived that families play a significant role in ED transfer decisions as they frequently react to a resident change of condition as a crisis." (34)

"I think the biggest reason [for NH-ED transfer] is the family piece - because you can know whatever you know, and want to do whatever you want to do, but if mom or brother or sister or DPOA (durable power of attorney), or whatever, doesn't agree with that, it's very difficult to change their mind." (34)

"The husband, daughter and two sons arrived to the ED and insisted on a full code status and wanted the 


\section{Lack of access to} community palliative care

patient intubated." (26)

"This inability to have the family understand the current situation created an ethical dilemma for the clinicians, in part because the treatment wishes of the family seemed incongruent with the family's original goal of having the patient die at home." (26)

"Providers perceived that families often felt insecure about the care provided in the NH setting and how that frequently seemed to influence family preference for ED transfer." (34)

"Sunday evenings are big for skilled nursing facility transfers, because families come to visit and they don't like what they're seeing." (34)

"The patient, who lacked decision-making capacity at the time the ambulance was called, later expressed anger that her husband had brought her to the hospital ("I was going to kill him for shipping me [to the hospital]. What do I want to hang around like this for.just to suffer is all I am doing." (20)

"Patients may be sitting there breathing at 40, but they usually aren't the ones that initiated coming into the hospital, it is usually the family that is scared of what they are seeing." (19)

"They are not coping at home ... and they're not actually the patient of the Oncology Unit anymore because . .. they're no longer offering active treatment. So this patient gets lost in limbo, because ... . they're a palliative patient ... [and] we can't send them home because they're not coping at home, and there's nowhere else outside to send them to because the [palliative care] facilities are all full." (21)

"To me, it's a reasonable investment of my time if it's a bona fide emergency. If this is something that's been going on for two months and simply hasn't been addressed . . . then that's an unreasonable demand on me." (21)

"Measures to improve access for people with advanced cancer to community and outpatient services should also be facilitated, so that ED is not relied upon to manage the predictable events and subacute symptoms that can be anticipated for patients with advanced cancer and managed in more suitable environments." (21)

"The need for palliative care specialists often occurs at night and on the weekends, when the palliative care team is often unavailable. Having a palliative care team that is responsive to this need will further enhance collaboration with the ED" (28)

"Optimal care for advanced cancer patients would involve remaining in the community and avoiding ED attendance and hospital admission. ED attendance was widely seen as a failure and the ED a less than ideal environment for patients with advanced cancer. I think we go to great lengths to avoid presentations to emergency departments unless we really have to." (24)

"Commonality of views across healthcare disciplines of the constituents of optimal care in the setting of advanced cancer; and that this involved high quality communication, planning care and decision making by those healthcare providers most involved in the patient's care and community-based care with ED to be avoided if possible." (24)

"Patients would benefit from clear information on where to seek appropriate help and from whom, especially outside office hours. In such cases, primary care 'out of hours services' tended to advise patients to call for an ambulance to take them to hospital, leading to an admission via the emergency department." (30)

"The lack of access to appropriate and timely palliative care support and expertise in the NH setting may be a contributing factor to frequent and often burdensome ED transfers at the EOL." (34)

"No the thing is the hospital is the last resort you know what I mean and I wouldn't do it, I wouldn't phone for a doctor or a medic unless I thought there was something seriously wrong." (30)

Lack of direct access to secondary care
"Whilst ideally patients would go from being managed at home . . . because that's probably the best thing for them, to inpatient palliative care, realistically it's probably not always possible. A lot of people will ... have acute deteriorations when they are going to have to come to the ED." (21)

"They relied upon the ED to provide initial assessment and management of patients known to their services after hours, in acute crises and when no inpatient palliative care beds were available... I also had one lady that was terminal, the family weren't coping, wasn't able to get direct admit into a palliative care unit, and was 
Palliative care consultation in the ED actively dying on admission to the emergency department. And the emergency department really did a great job" (24)

"Health professionals described unclear pathways leading to patients' unscheduled admissions, often out of hours, via emergency rooms. These were universally deemed to be inappropriate." (30)

"Patients with advanced cancer were frequently directed to the ED because direct admission to an inpatient bed or timely outpatient review was not available." (21)

"Solutions may include both communication and structural changes, such as improved outpatient symptom management; improved communication between outpatient and ED providers; predetermined care plans; greater transparency about the reasons for long wait times; ways to mitigate wait times in palliative care patients, such as direct admissions or curtailed workups; or special pathways that assure pain needs are addressed quickly." (20)

"...if we can avoid it we get the patient to come straight to clinic. .... [if] for some reason that's not feasible, we let them do the second sort of fall-back position [which] is coming to ED, so you would then you expect that ED is going to do the initial assessment." (24)

"We would be delighted if that happened and you could get direct admissions to these wards (cardiology), you could get the enthusiastic heart failure nurses engaging in the ward instead of having to chase around the place to try and find who is where and a guy in the orthopaedic ward ... or the respiratory ward and whatever else it is so we just try and make admissions easier to come about and to arrange, to organise and more pleasant to happen." (30)

"I think ... if there is that clearer path it keeps everybody right from primary care providers through secondary and through palliative service." (30)

"Three residents suggested a palliative care "hotline," similar to the toxicology hotline, to improve access to information about pain, symptom management, and home-based services such as hospice. Two residents suggested an intervention similar to the rape crisis intervention, training a group of nurses to provide excellent palliative care and be called on as needed." (19)

"We have a very scattered role in terms of keeping everybody on a plane of going toward better health. This needs a lot of sensitivity, which takes time and finesse, a little bit of the ability to understand where a family and a patient are coming from. And you cannot get that in a five-minute interaction." (27)

"Activating palliative care consult in the ED could be useful, especially because a lot of our patients tend to be noncompliant with follow-up or go to many different providers. So if you were able to activate the palliative care team in the ED, they may have at least one consistent person that they can talk to." (27)

"Emergency physicians in our study overwhelmingly acknowledged the many potential benefits of enhancing their own palliative care skills, as well as having a palliative care team provide services for more complex cases." (27)

"“'Unless the family opts-out, there should be certain criteria and a screening process to decide whether palliative care should get involved." (27)

"Purely from a time perspective, if you have a palliative care team that can clarify goals of care, which is generally a very time-consuming process, especially on a busy day when you're caring for 50 patients that could be immensely useful." (27)

"No, I think that I saw [the palliative care providers] at about the right time, because it takes a certain amount of time for a person to realize that the time for focusing on a cure has ended, and that there will be no active treatment of disease itself to try to cure it. It takes a person a certain amount of time to take all of that in." (20)

"Patients and caregivers in our study, who were familiar with palliative care from a previous hospitalization, outpatient visit, or hospice, were open and welcoming of the concept of palliative care clinicians in the ED. However, if this is not a coordinated approach, there can be a perception of an adversarial relationship between providers, which has the potential to be more damaging to patient care than helpful." (20) 
proposed suggestions for better integration into ED practice. To standardize the utilization of palliative care services, many physicians recommended the use of a diagnosis-driven approach by creating a checklist of criteria, such as life expectancy and disease state, that automatically alerts the emergency physician when a palliative care consult is appropriate. This could also increase palliative care visibility in the ED and act as reminders to the emergency staff that referral to this service is an option." (28)

"The need for palliative care specialists often occurs at night and on the weekends, when the palliative care team is often unavailable. Having a palliative care team that is responsive to this need will further enhance collaboration with the ED." (28) 
eTable 4. Themes identified in synthesis of 19 studies: Education and training

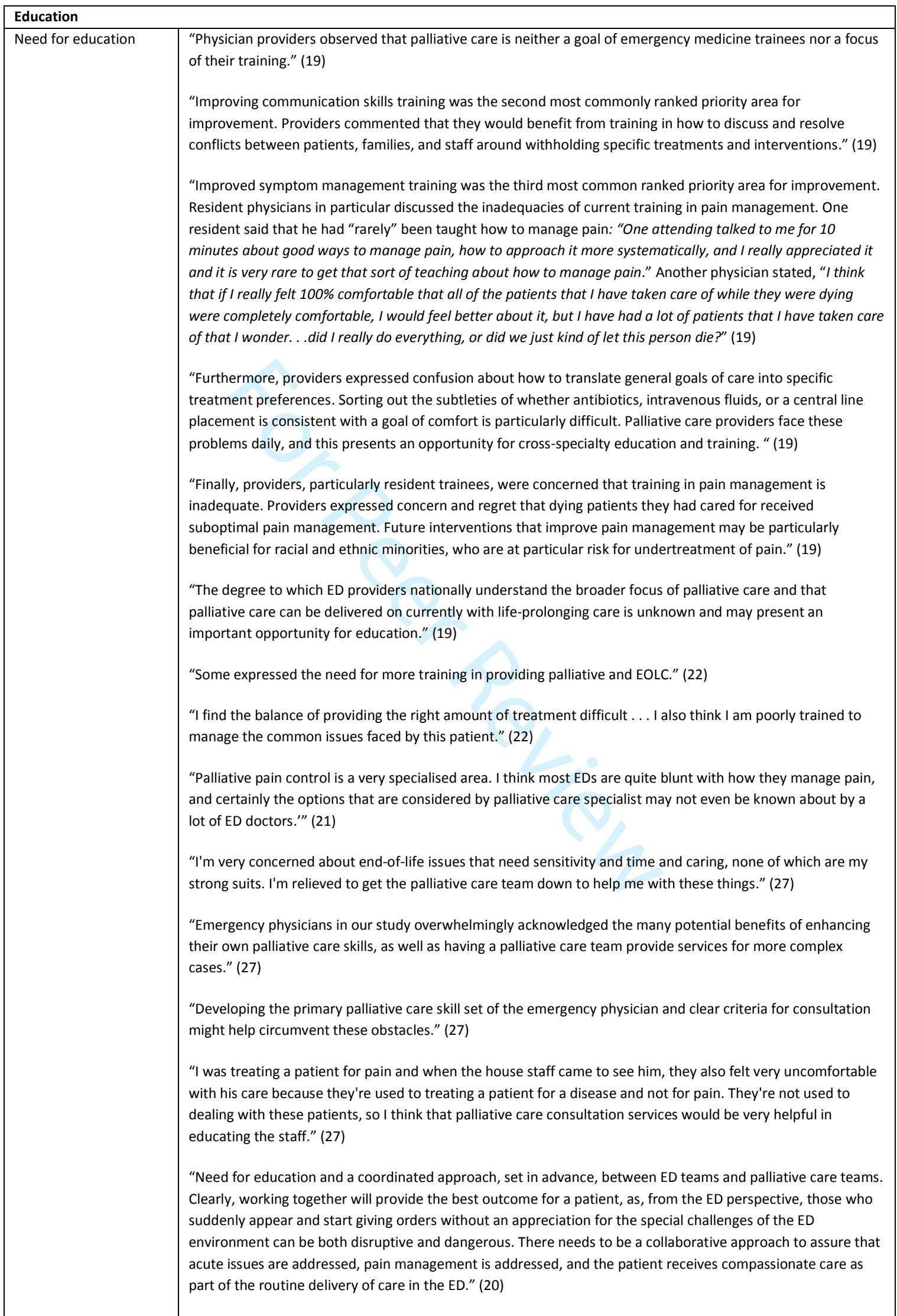



potential risk of an earlier death as a side effect of medications is acceptable (the "double-effect" principle)." (20)

"Many ED physicians acknowledged limitations in providing basic palliative care due to lack of training in that area." (28)

"Similarly, respondents reported that their training in emergency medicine did not provide the necessary communication skills to have these types of end-of-life discussions with patients and family. "I think a lot of us get a little bit blunt in the way we communicate things. And sometimes things need to be said a little bit differently with a little bit more care and comfort." (28)

"Lack of training and knowledge were common barriers noted, and it was generally felt that this material is important to integrate into emergency physicians curriculum and continuing medical education (CME)." (28)

"However, this study has highlighted factors underlying communication gaps, namely a lack of understanding of the demands and stressors placed on colleagues in other areas and a lack of appreciation of their role and skills.... Improved understanding and trust could be enhanced by combined education sessions, such as case discussions following the transition through the ED of a person with advanced cancer and complex care needs." (24)

"Communication skills are taught to healthcare students and professionals and emphasised as central to providing high quality clinical care to patients. Teaching of these skills could be broadened to encompass communication with healthcare colleagues." (24)

"There are many contributing factors that could influence avoidance and the low acceptance of death by emergency nurses such as personal experience and beliefs, or a lack of education and support, it could be argued that death in the ED was viewed as a failure to save a life." (13)

"Emergency nurses would benefit from palliative care education and the availability of specialty palliative care equipment while EOL care continues." (13)

"These trajectories offer an insight into end-of-life care giving for all emergency professionals and can be used within undergraduate and continuing education to identify the shortfalls in end-of-life care within the ED." (25)

"Within education there are implications at both undergraduate and postgraduate level. The current lack of consistency within nursing and medical curricula needs to be addressed, focusing on the effect of end-of-life care delivery in critical care areas and building awareness of the nonphysical needs of the subtacular dying to ensure a positive effect on those providing the care and consequently those receiving it. At postgraduate level, the focus needs to turn to supportive practice for trained staff in relation to end of life." (25)

"Respondents self-rated knowledge and formal training in palliative care seemed to correspond as the majority of nursing and medical staff both reported having 'working knowledge' and 'on the job training' and very few rated their knowledge as 'extensive' or reported having formal qualifications, respectively.... Sought further education in areas, such as end of life communication and ethical issues." (32)

"Nursing staff expressed less confidence than medical staff on a number of topics that suggest the need for more nursing-focused education programmes." (32)

"End-of-life communication skills and ethical issues were the most popular education topics selected by respondents." (32)

"ED staff felt confident delivering clinical aspects of palliative care, they lacked understanding of the scope and goals of palliative care, and potentially the communication skills to handle end of life discussions. Possible next steps include the development of education and training programmes that focus on providing ED staff with the knowledge and skills to identify patients with unmet palliative care needs, initiate end-of-life discussions during the ED consult and follow-up with appropriate referrals." (32)

“One physician suggested a 2-pronged solution: public education to increase the prevalence of ADs and universal electronic registration of ADs to improve the clinicians' access to them." (35) 
"Didactic presentations through lectures, workshops, or presentations by members of the palliative care team were expressed as being an ideal training format. Emergency physicians identified important educational topics in their training such as accurately understanding palliative and hospice care, how to approach palliative care cases, tending to patients with chronic, non-lifethreatening needs, and accurately identifying patients for whom palliative care is pertinent. Furthermore, some suggested incorporating direct patient care experience in the ED by allowing physicians to work through actual cases in collaboration with the palliative care team." (28)

"First, providing educational materials and courses that have been developed from the ED perspective Education in Palliative and End-of-Life Care for Emergency Medicine (EPEC Emergency Medicine) should be included in ongoing CME." (28)

"Progression through these three stages generally seems to occur through learning from multiple patient and relative encounters. The way individual nurses respond to these challenges seems to determine whether they develop appropriate skills and learn to manage the potentially harmful effects of regular exposure to death and dying." (11)

\section{Legal concerns}

"Furthermore, although physicians described sometimes thinking that resuscitation was not in the best interest of patients, they also described feeling legally compelled to resuscitate patients without clear DNR documentation." (19)

"The perception that futile care is frequently provided in ED is an important new finding... some have suggested difficulties understanding legal and ethical responsibilities may contribute to the frequency of futile care." (22)

"In the vast majority of cases, the family wants more aggressive therapy than the practitioner thinks is reasonable. The challenge is to bring the family to what we consider to be a more reasonable place." (27)

"However, many physicians in our study would welcome an opportunity to avoid aggressive interventions that they may feel are not in their patients' interests but feel compelled to do because of pressure from family members or medicolegal concerns. Providers believe that legal issues impair their ability to forgo certain treatments, even when the potential for harm outweighs the potential for benefit. This is consistent with other studies of emergency physician attitudes and beliefs regarding the practice of defensive medicine. Most emergency physicians admit to ordering more tests than medically indicated because of fear of liability" (27)

"Am I doing what is right for the patient? Or am I doing what is medico-legally right?" (27)

"We're all stuck feeling like if we aren't aggressive in our treatment, fingers will be pointed at us when it's abundantly clear that the most aggressive medical care isn't the best care for the patient. That's where palliative care can be really helpful. Once they've involved, a lot of people relax their medicolegal concerns and you can actually begin to treat the patient the way they ought and want to be treated." (27)

"NH health care providers further related that they often made transfer decisions against their best clinical judgment because of this family influence and for fear of potential repercussions (e.g., complaints, lawsuits, and poor outcomes)." (34)

"People have really different views of what 'comfort measures only' means. Does that mean you can give them fluids? Is that comfort, or is that intervention? Can you give them antibiotics? Is that comfort, is that intervention?" (19)

"Furthermore, providers expressed confusion about how to translate general goals of care into specific treatment preferences. Sorting out the subtleties of whether antibiotics, intravenous fluids, or a central line placement is consistent with a goal of comfort is particularly difficult. Palliative care providers face these problems daily, and this presents an opportunity for cross-specialty education and training." (19)

"Advance care plans (ACP) were viewed as a means to undertake preparatory discussions and appeared strongly supported with almost all staff agreeing that they preferred patients with advanced cancer to have an ACP in place, and that this made caring for the dying in ED easier" (22)

"Almost all respondents agreed that ACP make it easier to care for dying patients in the ED, consistent with the 
published literature. While data regarding the use of ACP in Australian ED are limited, a recent study and the authors' own experiences suggest it remains infrequent. The communication process involved in preparing an ACP and then the documentation of its purpose and making it easily available would seem to address many of the concerns raised by ED clinicians, perhaps explaining its almost universal popularity. Although ACP should not be seen as a panacea, particularly given some of the inherent difficulties with documenting a complex set of wishes that are likely to change over time, the process of communication around goals of care is desirable and should be encouraged" (22)

"Improved planning for foreseeable events is likely to be assisted by increased promotion of advanced care planning throughout Australia." (21)

"Discussions about goals of care and important management decisions should ideally occur with a doctor who knew the person with advanced cancer well, usually an oncologist or palliative care physician. Advance care plans for people with advanced cancer, with established goals of care and plans made for potential complications, were advocated." (24)

"Driving this feeling of panic that influenced families was absent or inadequate advance care planning discussions and decisions. Without medical orders reflecting treatment decisions, providers articulated that the default was to provide all available medical treatment, including ED transfer." (34)

"Our clinician interviews raised 3 major issues: discomfort in discussing end-of-life care in the ED, difficulty in interpreting $A D s$ as they apply to the clinical situation at hand, and proposed solutions for improving communication about end-of-life care in the ED." (35)

"People have a phobia, they think that if they have an AD we're going to kill them or something or use them for organ donation." (35)

Preparation for death

Preparedness of patient $\quad$ "The ED staff expressed significant frustration about the frequency of patients with advanced cancer attending ED who had insufficient understanding about their disease and prognosis, which they felt was because of inadequate communication and poor future planning by their usual care providers." (21)

"ED clinicians perceived that a substantial proportion of patients and their families may be unaware of the stage of their illness, that death may be imminent and that they may be underprepared for the dying process" (22)

"Our finding that patients and caregivers were unprepared to manage symptoms at home suggests the need for improved education about end of life symptoms and system changes to rapidly respond to the needs of patients in the outpatient setting." (20)

"Many patients and caregivers also expressed anxiety over the implications of their symptoms in relation to their overall prognosis and were looking for more information about their disease. Although communication may not have been optimal, many of the questions they sought answers to were not easily answered by ED providers" (20) providers thought that family members, rather than patients, were uncomfortable managing these symptoms at home." (19)

"It is one thing to come up with an advanced directive; it is another thing to be faced with the actual situation of Grandma or Mom at home having trouble breathing. There is fear and hesitation once things are actually happening. A lot of times people just need a doctor, a caregiver, a nurse, a friend, or a family member to help support them and say 'it is okay to get through this'." (19)

"This finding emphasizes the high toll of home-based caregiving and raises questions about whether earlier introduction of hospice, which provides support and education to family members, might play a role in reducing family fear and preventing some of these admissions. Although going to the ED may be the best course for some patients, for others, these findings suggest a need for strategies to treat symptoms effectively at home and prepare caregivers for distressing end-of-life symptoms." (19)

"Many providers perceived that families often seemed emotionally unprepared for their loved one's decline in health and ultimate death." (34) 


\begin{tabular}{|l|l|}
\hline $\begin{array}{l}\text { ". .they [family] were not ready at that time to initiate hospice, so one day he really exacerbated, he went to } \\
\text { the hospital, CHF exacerbation, and he expired at the hospital. . We have had two of these instances recently: } \\
\text { one was metastatic lung cancer, and the other was CHF. And they were both in one month. They [the families] } \\
\text { were just not ready at that time for hospice, even though we saw it. We did the consultation, the notes were } \\
\text { there from hospice that they're ready physically, however, mentally and psychologically, they were not ready } \\
\text { to give up yet." (34) } \\
\text { "The participants reported that the acceptance of death by a patient or their family facilitated the movement } \\
\text { of the patient out of the ED and to an environment that promoted the elements of a good death." (13) } \\
\text { "The family had either a misunderstanding of the role of hospice, a lack of experiential knowledge surrounding } \\
\text { what the signs of impending death were, or what death actually looked like." (26) } \\
\text { "Attempts at educating the family about the role of hospice and preparing the family for imminent death } \\
\text { seemed to be unsuccessful because of the family's sense of panic, feelings of being overwhelmed, and fear of } \\
\text { the patient's immediate death." (26) }\end{array}$ \\
\hline
\end{tabular}


Table 1. Enhancing transparency in reporting the synthesis of qualitative research: the ENTREQ statement

1. Aim.

2. Synthesis methodology

3. Approach to searching

4. Inclusion criteria

5. Data sources

6. Electronic Search strategy

7. Study screening methods

8. Study characteristics

9. Study selection results

10. Rationale for appraisal

11. Appraisal items

12. Appraisal process

13. Appraisal results

14. Data extraction

15. Software

16. Number of reviewers

17. Coding

18. Study comparison

19. Derivation of themes

20. Quotations

21. Synthesis output

\section{Page number}

1 (abstract) 3 (text)

1 (abstract) 4 (text)

1 (abstract) 4 (text)

4

4

4, eTable 1

4

5 , Table 2

5, 6 (PRISMA FLOW CHART)

4

4

4

7, eTable 2

4

5

4

4-5

5

5

8-11, eTables 3,4,5

8-13, 